XVI.-The Early Metallurgy of Copper, Tin, and Iron in Europe, as illustrated by Ancient Remains, and the Prinitive Processes surviving in Japan. By W. Gowland, Esq., F.S.A., F.C.S., Associate of the Royal School of Mines.

Read 18th May, 1899.

As the rude and primitive processes by which metals were extracted from their ores and adapted to the uses of man in early times are fast disappearing, and will soon cease to be practised in the few regions of the world where they still survive, it has appeared to me to be advisable that some record should be preserved of them before they fall entirely into disuse and become forgotten.

To many of these primitive processes a unique interest attaches on account of the efficient manner in which their ends are attained, notwithstanding the rudeness and simplicity of the appliances employed; but to us they possess in addition an interest of a wider and deeper character, by reason of the light which they throw on the unwritten history of early metallurgy in Europe.

Japan, owing to its remote geographical position, to its almost complete seclusion until recent times from foreign, especially European, intercourse, and to the persistent adherence to the implements, appliances, and methods of their ancestors which characterised its people, presented, when I first arrived there in 1872, a most favourable field for the study of metallurgical processes in their primitive forms. I hence began at once a series of systematic investigations of the methods and appliances then in use, and continued the research during my long residence in that country. A condensed résumé of these investigations and their bearing on the elucidation of the primitive metallurgic arts of Europe, I will now endeavour to lay before you, as briefly as possibly, in the following pages.

It is hardly necessary to say that in other regions of the world, especially in VOL. LVI. 
India and the interior of Africa, similar primitive metallurgical processes also survive. I have, however, confined my remarks almost exclusively to those of Japan and Eastern Asia, as I have had special practical experience of these, and with one or two minor exceptions, which are represented in the old manuscripts exhibited, I have seen them all in actual operation.

In my account of the early furnaces and processes of metallurgy in Europe, I have purposely taken no cognisance of the statements of classical writers, although many of these, doubtless, contain at least some germs of truth, even when their exact meaning is not obvious, and I have preferred to base all my descriptions and deductions on the actual objects of metal and other remains of metallurgical work which have been unearthed from time to time.

The remains which are of chief importance for our guidance in the determination of the manner in which the metals were obtained and treated by early man are rude excavations along the surfaces of mineral-veins, or shallow burrows in the sides of hills, from which he obtained the metal-bearing ores; heaps of slag from smelting operations; ruins of furnaces; crucibles and melting hearths; and stone and clay moulds. Such are the materials on which are written, sometimes in doubtful language, the records of the early attempts of man to subject the metals to his use.

Before proceeding to consider the strictly metallurgical operations, I will review briefly, and as far as the evidence available permits, the mode in which in prehistoric and proto-historic times the metalliferous ores were obtained, and the treatment to which they were subjected to render them suitable for smelting in the simple furnaces of those days.

In the remote period when the metal copper was first produced by smelting, there is every reason to believe that the ores from which it was obtained were originally found as pebbles or boulders in the beds of streams, or as rough lumps on mountain sides, near the outcrops of veins, where neolithic man was accustomed to search for stones suitable for the manufacture of his implements. The gravel and pebble beds of rivers were certainly then and for a long subsequent period the only sources of tin.

Similarly in Scandinavia, the only ore from which iron was extracted, even until comparatively recent times, was bog iron ore, which was collected near the margin's of lakes and in the shallow beds of rivers. Even within our own times examples of similar primitive conditions have not been wanting."

" Dr. Lamborn in A Rudimentary Treatise on the Metallurgy of Silver and Lead (London, 1861), 132, says: "The hunter and settler in Missouri, in the United States, early learned to procure 
Mining operations are decidedly of a later period, when considerable advance had been made in the uses of metals, and when in the case of copper a larger demand for it had arisen than could be supplied by the collection of accidentally occurring lumps of ore.

The earliest traces of mining or excavations in search for ore are the shallow holes or pits dug into the mineral vein where it crops out at the surface of the ground, which have been found in Wales, Spain, and Upper Austria.

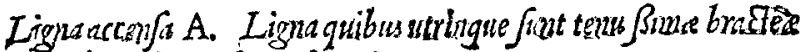
of pase B. Cinzeculises C.

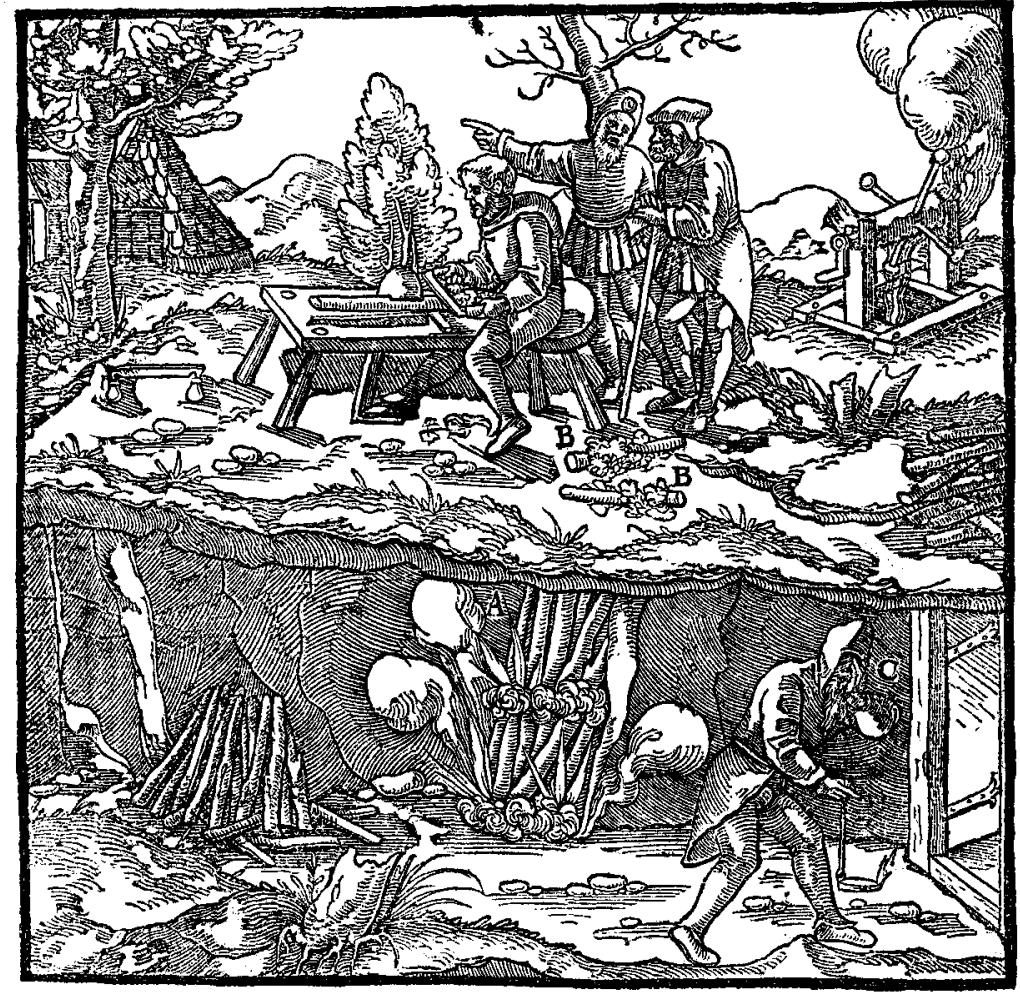

Fig. 1. Mining by the aid of fire, termed "fire-etting," as practised in the Harz in the 16th century.

the lead necessary for making their shot and bullets by building a fire in the hollow of a fallen tree or in an old stump, smelting the pieces of galena which they picked up on the surface." Another example is given by Dr. Layard, in Nineveh and its Remains (i. 224). He remarks: "In these mountains (Tiyari Mountains), particularly in the heights above Lizan and in the valley of Berwari, mines of iron, lead, copper, and other minerals abound. Both the Kurds and the Chaldeans make their own weapons and implements of agriculture, and cast bullets for their rifles, collecting the ores which are scattered on the declivities or brought down by the torrents."

$$
2 \times 2
$$


Almost contemporaneous with these are rude burrows at no great depth below the surface, which from their irregular directions appear to have followed the richest parts of the veins.

To this time belong the stone hammers and deer horn picks which have been found in ruined workings in Britain and other countries.

These hammers of stone and picks of deer horn at first sight would seem to be singularly inefficient tools for breaking out the ore from its matrix of harder rock; but primitive man had evidently observed that stones are splintered by fire, and had applied that knowledge to aid him in his mining operations. This is

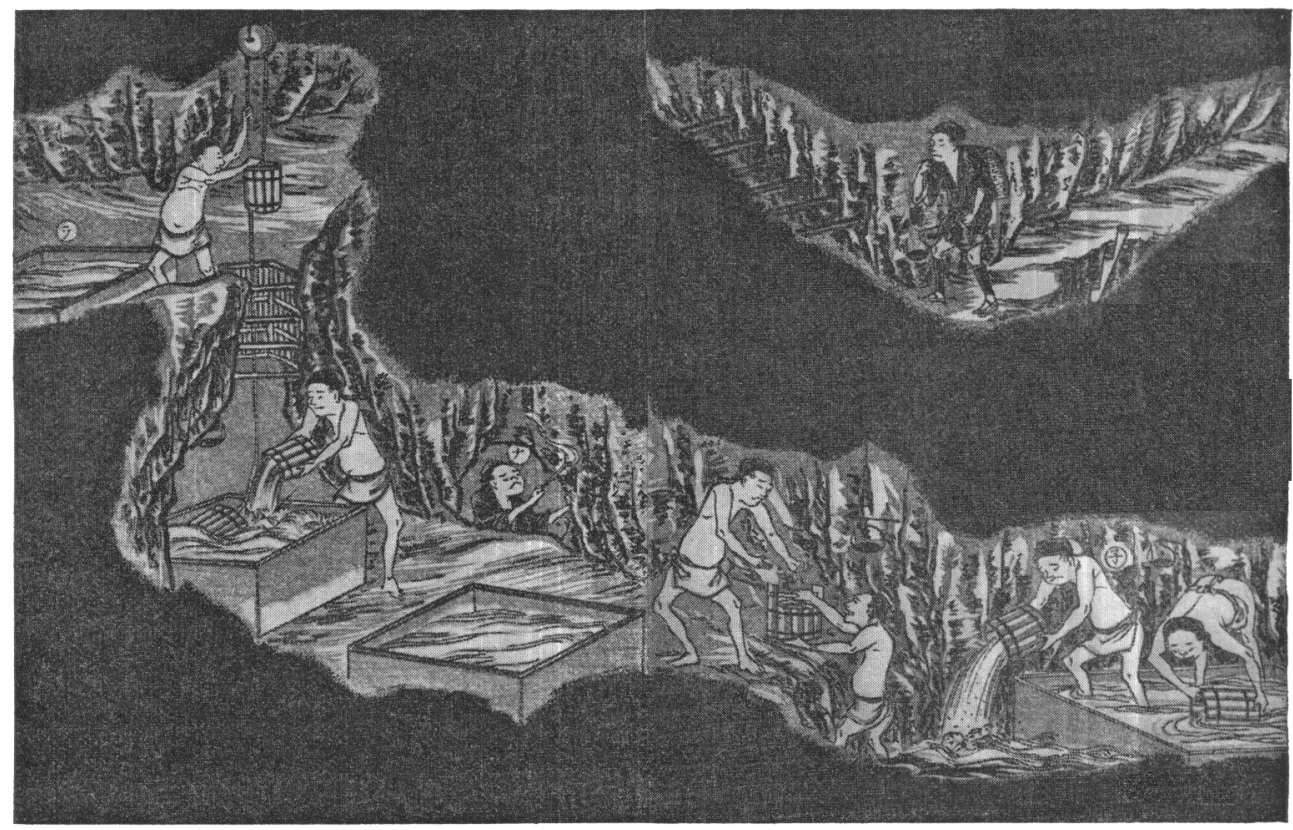

Fig. 2. The underground workings of an old Japanese mine.

indisputably proved by the remains of charred wood and charcoal which have been found at the ends of his burrows in North Wales, Cardiganshire, the Mitterberg in Upper Austria, and other places. This method of mining by the aid of fire was conducted as shown in fig. $1 .^{\mathbf{a}}$

Billets and faggots of wood were piled up against the face of the ore in such a manner that when set on fire the flame should play against the mineral mass to be disintegrated, the result being that a considerable quantity of the ore was splintered off in flakes, and the remainder, to a certain depth, was so much shattered that it could easily be detached by almost any kind of tool.

a The illustration is taken from Agricola, De Re Metallica (Basileæ, 1556), 80. 
The method was still in use in the copper mines of Rammelsberg in the Harz in 1878, where in one part of the workings an ore of extreme compactness could be more economically extracted by it than by blasting with gunpowder.

Some of the smaller mines in Japan, which I visited in 1874, afford an exact parallel with these earliest mines in Europe; the excavations being merely burrows, in some places so small that they could hardly be traversed even by crawling on hands and knees, and winding about in a tortuous manner avoiding all the hardest and poorest parts of the vein (fig. 2).

The mode of extracting the water from the lower workings by means of wooden buckets as shown in the figure is also exactly similar to the practice which prevailed in the early European mines, even up to Roman times, where staves of bucket-like vessels which can only have been used for carrying water have been occasionally found in their galleries.

After the ore had been obtained it was necessary to prepare it for smelting by reducing it to a coarse powder.

There is abundant evidence to show that the appliances in the earliest and even in later times for grinding the ore were simply modifications of those employed in the grinding of grain for food. Those discovered in the refuse heaps of most ancient mines consist chiefly of a lower stone with a rough hollow worn in its upper surface in which the ore was beaten and ground by a pounding stone acting as a pestle.

There are also found occasionally " rubbing" or "buckering" stones which seem to have been used after the manner of a muller; the ore being placed on the flat side of a larger block. One of these blocks which shows well the circular hollows produced by attrition is illustrated in fig. 3. It was found near

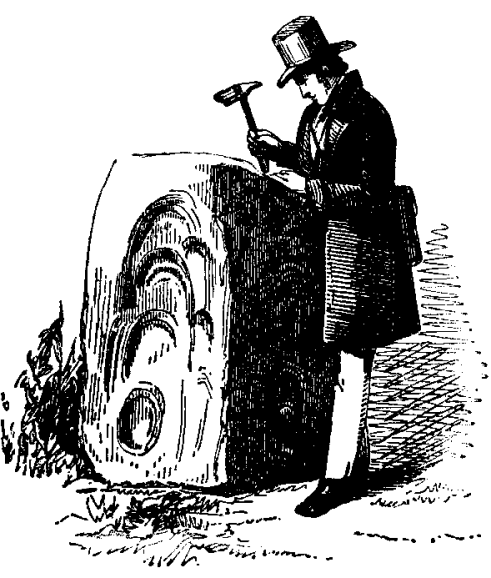
the ancient workings of the Gogofau mine, Caermar- Fig. 3. Block of stone on which ore was thenshire. ${ }^{a}$ These rude methods have not even yet died out in Europe, for near the ancient tin workings in Galicia, in Spain, women at the present day may be seen washing the ore after they have broken it between two rough stones.

a Note on the Gogofau, or Ogofau, mine, near Pumpsant, Caermarthenshire, by Warxington W. Smyth. Memoirs of the Geological Survey of Great Britain, i. 483. The illustration is taken from a woodcut in this paper.

b W. C. Borlase, Tin Mining in Spain Past and Present (London, 1897), 28. 
But no grinding appliance of prehistoric times which has yet been discovered is of a ruder character than that which was in use in Korea when I travelled through that country in 1884 .

It consists of a huge natural boulder of granite or gneiss set in the ground, with its flattest side uppermost and nearly on a level with the surface. Upon this

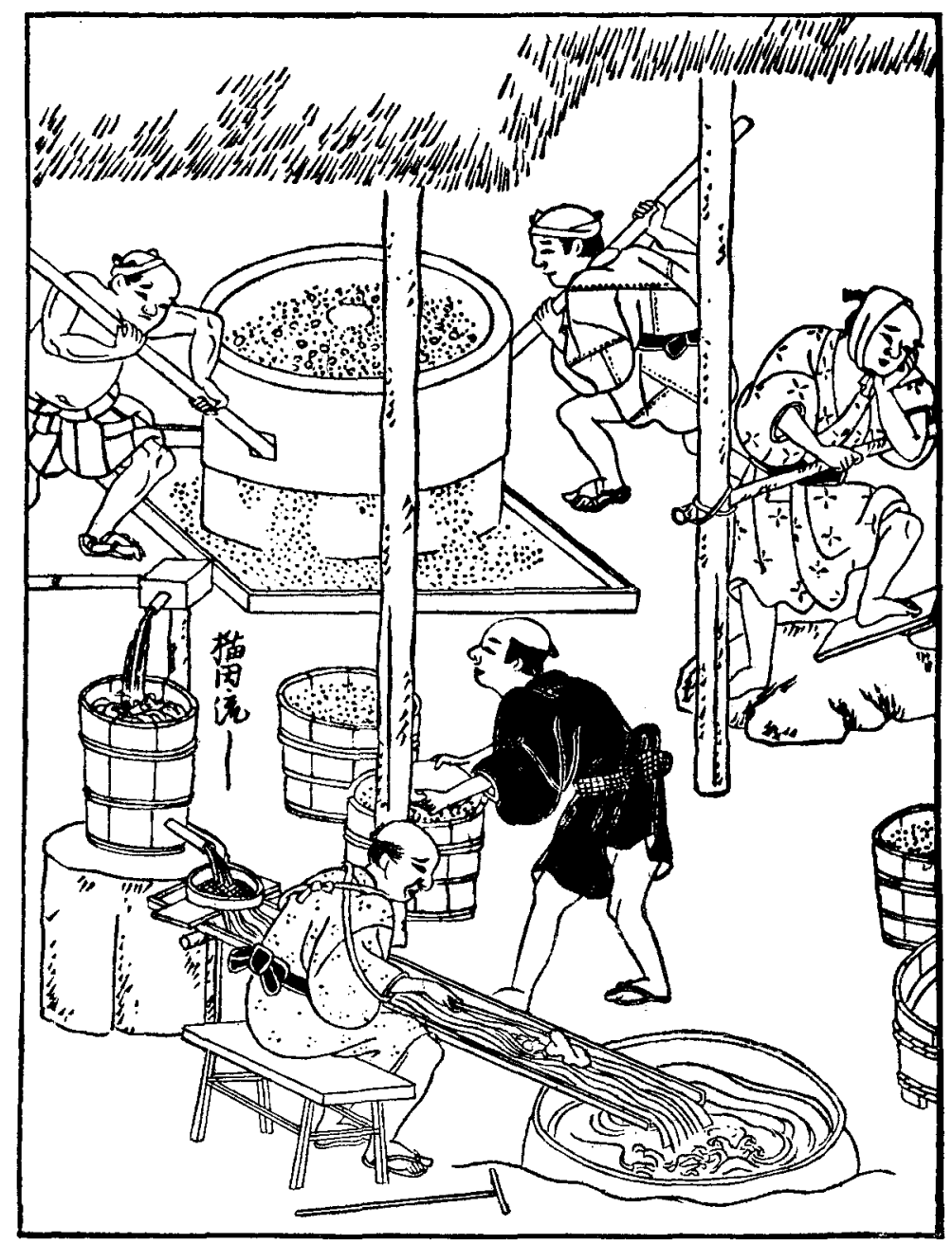

Fig. 4. Grinding ore in a quern. Japan.

rests another large boulder with a slightly curved face, to the sides of which two poles are lashed with ropes, or fixed with iron cramps, in such a manner that a rocking motion can be given to it by four men standing at the ends of the poles. The ore is crushed between the two boulders by rocking the upper one, and at the same time giving it a slight twist. 
The hand-mill or quern, an invention of great antiquity, is sometimes found in the débris left by the ancient miners, but it does not seem to have come into general use for ores in Europe until we reach or approach Roman times.

Perhaps one of the most interesting of the early examples in Europe of this use of the rotary corn mill is afforded by the ancient Greek mines of Laurion, in Attica, where an almost complete Roman mill, of the form so familiar to us which is seen in the baker's shop at Pompeii, was discovered in the old waste-heaps of the mine.

A curious feature of the later use of the quern in German mines is the mode in which they were driven in the time of Agricola, the author of De Re Metallica (1556), the motive power being treadwheels worked by men and by goats.

In Japan they are still in use at the tin mines of Taniyama, and at some small gold mines; modern appliances have, however, superseded them at all the larger workings, although up to near the end of the first half of this century the form shown in fig. 4 was in universal use.

The lumps of ore, which on account of their size are unsuitable for grinding in the quern, are broken up into smaller pieces by girls and women, with hammers, on large flat stones; a method identical with that practised in early times, excepting that hammers of iron are substituted for those of stone, the anvil still, however, being of the latter material.

In this preliminary breaking-up of the ore, to render it suitable for grinding in the quern, a curious kind of pounder is also in use, which, as far as I am aware, is peculiar to Japan and East Asia. It may be termed a foot stamp. The stamp consists of a horizontal beam of wood with an axle set near one end resting in bearings on an upright block of stone. To one end of this beam the stamp head, shod with iron, is fixed at right angles; and to it are also attached several large stones to increase the force of the blow. The other end is prolonged by fitting it to a plank of wood, and on each side of this is an inclined platform. In working the stamp the workman steps from the platform upon the plank at the end of the horizontal beam with one foot, resting his whole weight upon it, and thus raises the stamp head; he then quickly steps back to the platform, when the stamp head descends with great force into the mortar.

This also is an example of the application of an appliance for the preparation of grain to the preparation of ores, its original use being the decortication of rice. The mortar, like that of the early pounders, is of stone. 


\section{Nature of the Ores.}

As regards the kinds of ore which were first treated by primitive man for the extraction of metals, I think we may not unreasonably assume that they can only have been those which would yield the metals they contained by the application of a simple heating or melting process. The ores of tin and lead would present few difficulties, even at the very beginning of metallurgy, as the only ore of tin (cassiterite), and the common ores of lead (galena and cerusite), all admit of the reduction of these metals in the simplest manner.

The rich ores of iron, too, from which the metal was exclusively obtained until recent times, were all oxides of easy reducibility.

The ores yielding copper, however, consist of two classes, viz. sulphide ores and oxidised ores, which differ entirely from each other in character and composition, and require different methods of treatment for the extraction of the metal. The sulphide ores, as their name indicates, are compounds of copper and sulphur and usually iron, and from them the copper can only be obtained by a complex process involving two distinct operations, viz. first, a preliminary burning out of the sulphur by roasting the ore in a wood fire; and second, the smelting of the resulting roasted product.

The oxidised ores are oxides or carbonates of copper, which yield the metal by simply melting them in a charcoal fire.

Now it does not seem to be in the slightest degree probable that neolithic man, when he first extracted copper from stones, collected probably for the manufacture of his simple implements, could have invented or practised the complex process first mentioned, yet Dr. Wibel has advanced the view, and in this he is supported by Dr. Much, that all copper, without exception, even that of the earliest part of the Metal Age, was obtained by the difficult process of smelting sulphide ores. This view, apart from its improbability, can, I think, be shown to be untenable, as the chief argument brought forward in its favour seems to have arisen from the superficial knowledge of metallurgy possessed by these distingushed archaeologists. ${ }^{\mathrm{a}}$

Their chief argument is that sulphur in varying amounts is found by chemical analysis to be present in copper celts of flat types, therefore the copper of which

a Wibel, Die Kultur des Bronze Zeit, 33 and 40; Much, Die Kupfer Zeit in Europa (Jena, 1893), 267. 
these celts are made was obtained by smelting sulphide ores. But these amounts of sulphur do not prove this at all, for most simple oxidised ores contain small proportions of iron and copper sulphides, in the form of pyrites, and such is the affinity of copper for sulphur, that when these ores are reduced the copper obtained will contain quite as much of the latter element as is shown in the analyses quoted by Wibel. I may say, too, that I have hardly ever smelted an oxidised ore on a large scale without finding sulphur in the resulting copper.

The conditions under which copper ores were originally found in prehistoric times, and the nature of the ores which usually occur under these conditions, are also opposed to the conclusions of Wibel and Much. As I have already pointed out, the copper ores first discovered by neolithic man would undoubtedly be those occurring on the surface of the ground, either on mountain sides or in the beds of streams. Now, these could only be derived from the weathering of the outcrop of veins, i.e. the parts which are exposed at the surface of the ground. And as these parts in most veins, even in those which at a greater depth are composed of sulphides, consist of oxidised ores such as carbonates and oxides, it naturally follows that the ores first utilised would be of this character. It must also be remembered that in some localities we have absolute proof that the ores smelted were not sulphides. Thus in South Eastern Spain the only ores occurring in or near the sites of the famous finds of implements, \&c., of copper and bronze intermingled with those of stone, made by the brothers Siret, are copper carbonates, containing only a minute quantity of sulphide. In Switzerland, on the Murtchenstock on Lake Wallenstadt, and within reach of the lake dwellers of Robenhausen, the ore found in the débris of a prehistoric copper smelting works is not a sulphide, but a silicate of copper. In the ancient mine at Llandudno (North Wales) the ore is a carbonate.

It will, I think, be evident from the foregoing that these oxidised ores of easy reducibility were those first utilised by early man, and that the sulphide ores were only treated in later times when rude mining operations were attempted and considerable progress had been made in the metallurgic arts.

The first metal, the early metallurgy of which I propose to consider, is copper, and for this reason, that the primitive process and furnace by which it was and is still extracted from its ores in Japan can be and have been applied to the extraction of all the other useful metals.

VOL. LVI. 


\section{Copper Smelting in Japan.}

As I have already demonstrated in a previous communication ${ }^{\text {a }}$ to the Society, the earliest metal remains which have been unearthed in Japan are of bronze. They have been found chiefly in the Island of Kyūshü, where deposits of both copper and tin ores occur, the mines of the latter metal at Taniyama being the most ancient and extensive in the country. Near the boundary of the two adjoining provinces of Hyüga and Bungo, in which the remains of the ancient Japanese are specially numerous, there are also mineral veins of both copper and tin, but no traces of ancient workings have yet been found there. In both the neighbouring provinces on the west, however, stone moulds for casting sword and halberd blades have been dug up.

That copper was then known and worked in Japan, and tin also, and that the swords and other objects of bronze were not imported, is, I think, sufficiently proved by the occurrence of these stone moulds, and by all the weapons of bronze yet discovered being of forms peculiar to Japan. Now the skill exhibited in the production of these objects indicates a considerable advance in the knowledge of metallurgy. It is, too, much greater than that required for the mere extraction of copper from its ores, and as these ores are so abundant and so widely distributed in the country, I am of the opinion that they were smelted for the metal in very remote times.

The method which was practised, and the furnace employed by the early workers, still survive in use at several mines in Japan at the present time.

No appliance of primitive metallurgy could be simpler either in shape or construction than the Japanese furnace. It consists merely of a hole in the ground, yet by means of it until a few years ago all the copper, lead, and tin produced in the country was obtained, and although it is not used for iron, a skilful worker has no difficulty in producing that metal by its aid.

The furnace in its present form is shown in fig. 5. In constructing it a plot of dry ground is selected. In this an excavation measuring about 4 feet long, 4 feet wide, and 2 feet deep, is made, and this is filled with dry clay carefully beaten down. In the centre of this bed of clay a shallow conical-shaped hole is scooped out. The hole is then lined with a layer, about 3 inches thick, of damp clay mixed with broken charcoal, and the furnace is complete.

a "The Dolmens and Burial Mounds in Japan," Archaeologia, Iv. 475. 
It has no apertures either for the injection of the blast or for tapping out the metal. A blast of air is supplied to it generally from two bellows placed behind a wall of wattle work coated with clay, by which they and the men working them are protected from the heat. The blast is led from each bellows by a bamboo tube, terminating in a long nozzle of clay, which rests on the edge of the furnace cavity.

If oxidised ores, oxides or carbonates of copper, are used the metal is obtained in a single operation, which is conducted as follows: A roughly made

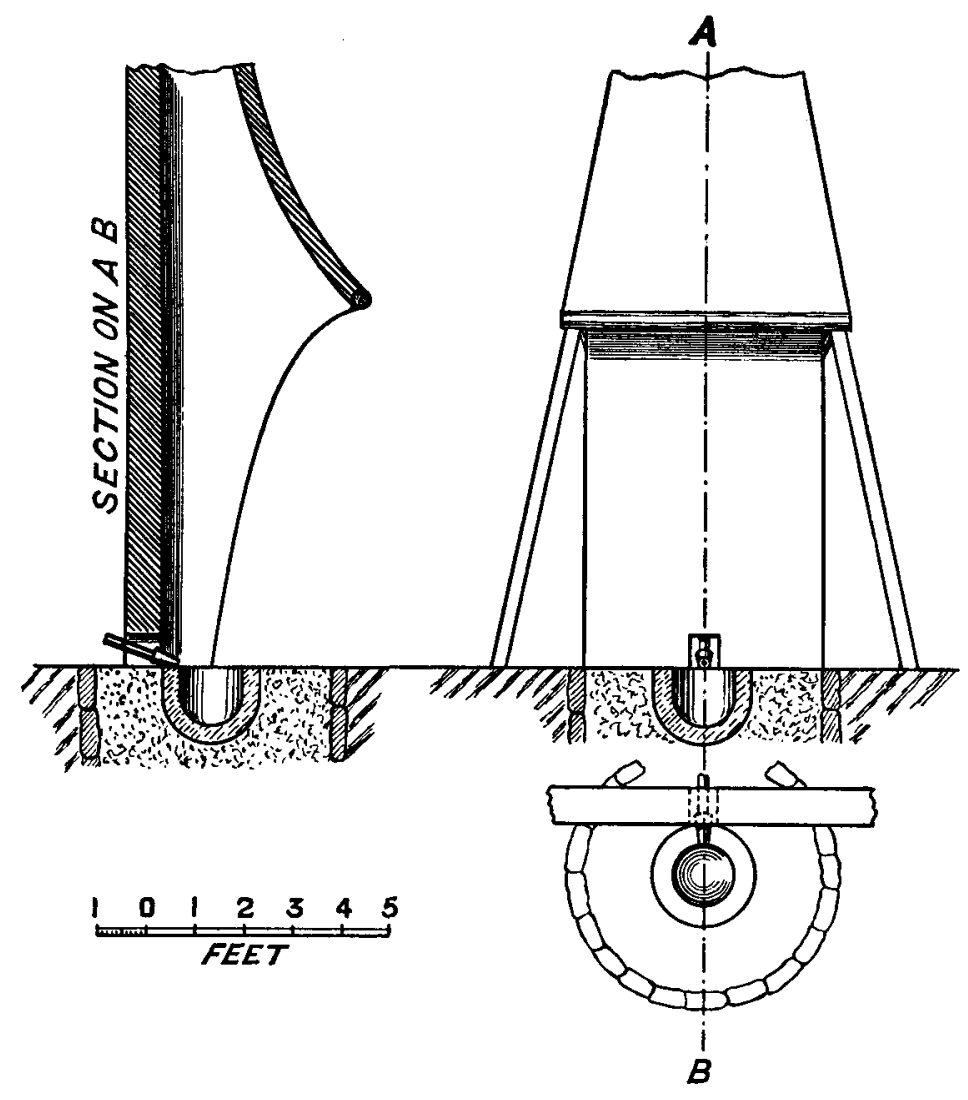

Fig. 5. Japanese smelting furnace.

thick semicircular lid of clay is placed over the blast pipes so that it almost covers the back half of the furnace. A small fire is then made in the cavity in order to dry it thoroughly. When dry it is filled completely with charcoal, upon which, when thoroughly ignited, a layer of fresh charcoal is placed, then upon this a layer of ore, then another layer of charcoal, and so on, until a conical heap of ore and charcoal covers the furnace.

$$
2 \text { Q } 2
$$


The bellows are then worked vigorously, when the ore is gradually reduced and the charcoal consumed, until after about one hour the entire heap sinks into the furnace cavity. The unburnt charcoal and slag which cover the molten copper are then raked off with a wooden rake. The metal is not removed by lading but

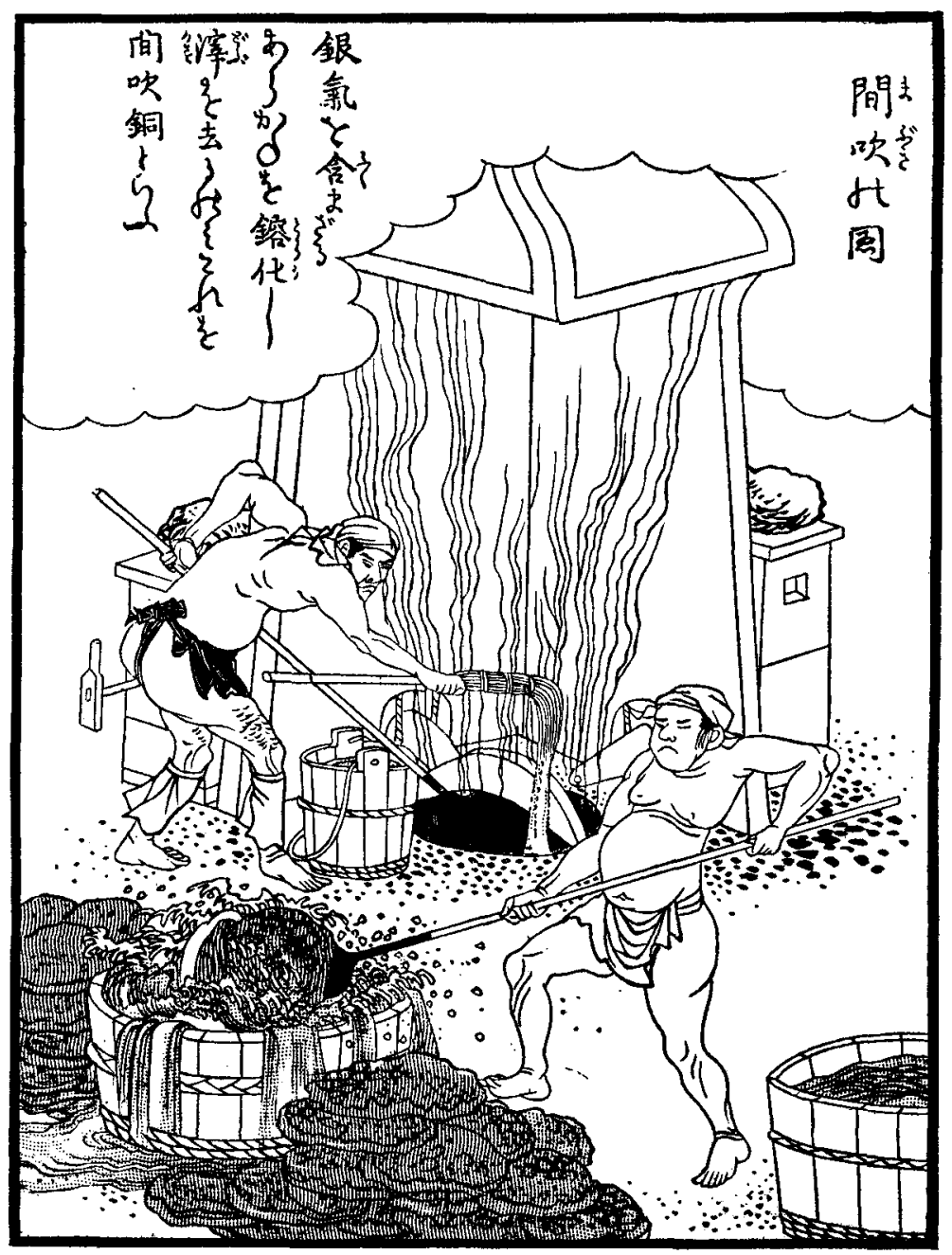

Fig. 6. Removing the copper in disi-shaped layers from the smelting furnace. Japan.

in the following manner: A little water is sprinkled on its surface with a straw brush, causing a thin layer of metal to solidify; this is at once raised up with a hook, removed on a shovel (as shown in fig. 6), and thrown into water.

Such is the primitive furnace and process which for probably twenty centuries 
have been in use in Japan, and in some districts still maintain their ground almost side by side with the more elaborate methods and appliances of modern metallurgy. It is worthy of note in connection with this process that the Japanese never, until recently, cast copper into ingots or blocks even when it had to be transported to great distances. This was probably because the thin rough dises could be broken more conveniently than thicker blocks into pieces suitable for remelting on

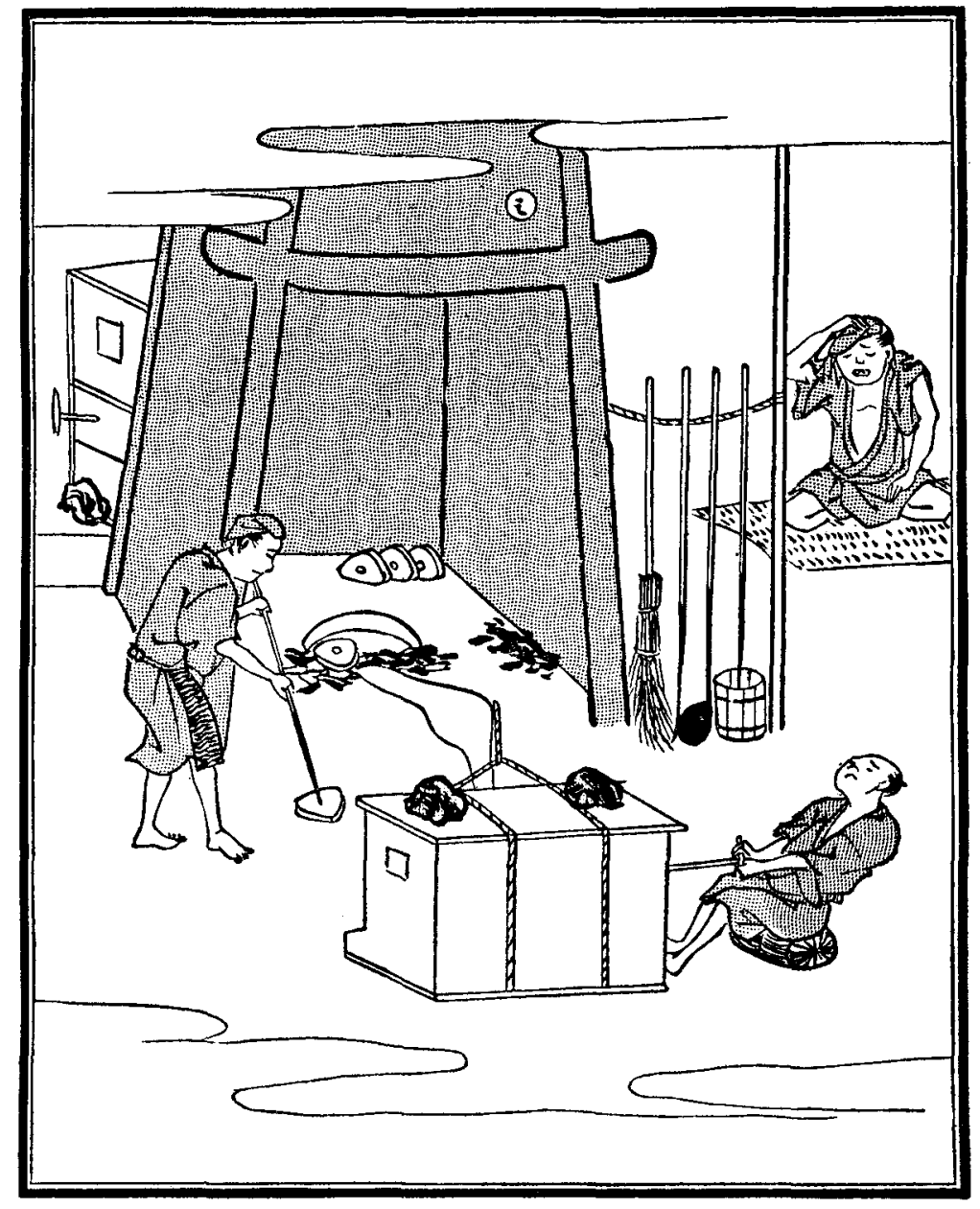

Fig. 7. Converting copper sulphide (regulus) into metallic copper by a blast of air. Japan. (See Footnote a.)

a When sulphide ores, such as copper pyrites, \&c. are treated, they are submitted to a preliminary roasting operation, by which most of the sulphur is removed before they are smelted. The smelting process is then conducted in the same manner as for oxidised ores, but as the melted product then consists partly of metallic copper and partly of copper sulphide (regulus), a blast of air is blown into it to burn out the sulphur, and convert the whole into metal, as shown in fig. 7. 
the small scale on which the operations of the Japanese metal worker are usually conducted. Even in the old mint in Tōkyō, during last century, the bronze alloy for the coinage was not cast into ingots, but was simply run out of the furnace in which it had been prepared on to the sand floor of the melting-room, where it was broken up by hammers, the pieces being remelted in crucibles.

In Korea, where a similar furnace and process is employed, the copper is

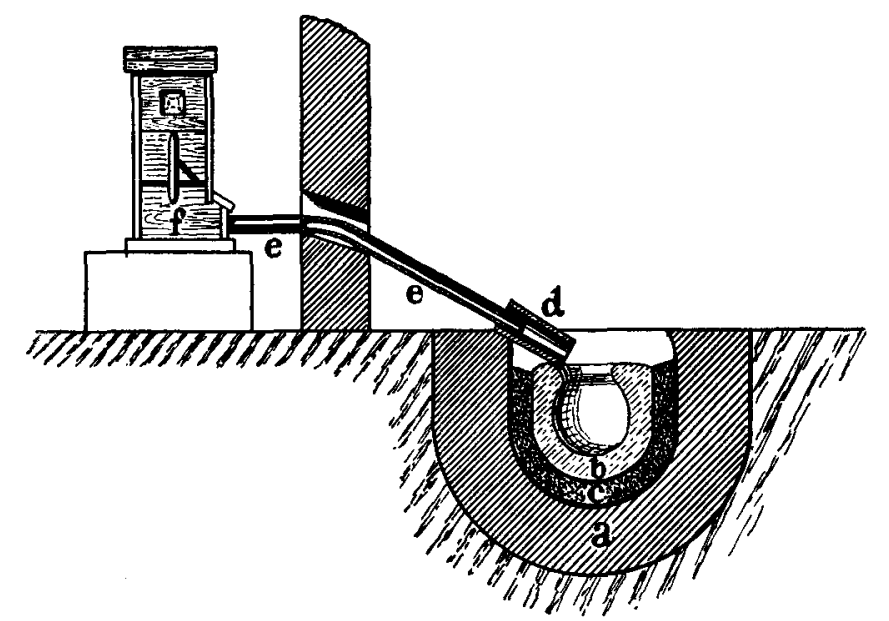

Fig. 8. Sectional elevation of Japanese furnace and cracible for casting copper.

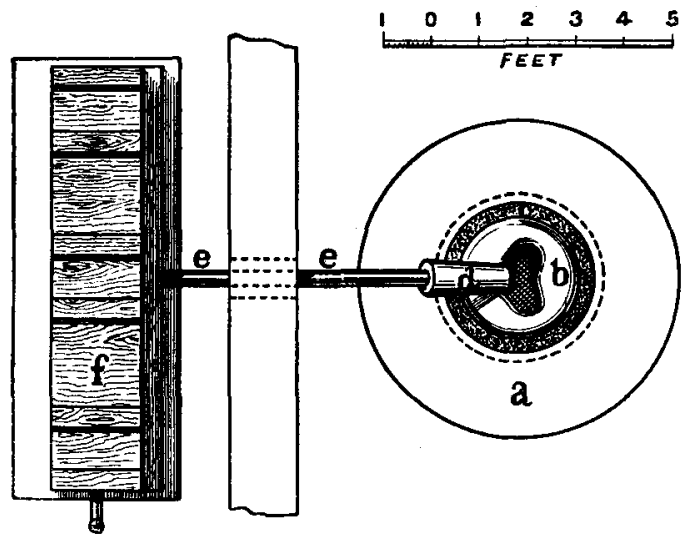

Fig. 9. Plan of ditto ditto.

removed in a different manner. It is allowed to remain in the furnace until it has nearly solidified, the cake of metal is then dislodged with a pole of wood, and quickly dragged out to a large stone, upon which it is broken into pieces with hammers. In this case the pieces of copper are identical in structure with those of European copper hoards. 
The copper thus produced in Japan is never cast direct from the smeltingfurnace into useful forms, but is always remelted in crucibles, a mode of procedure which undoubtedly prevailed in Europe during the early Metal and the Bronze Ages.

The crucibles used by the Japanese for this purpose are very much larger than those employed during those periods in Europe, and are also of an entirely different shape. Yet in composition, being made of ordinary clay mixed with chopped straw and chaff, they are precisely analogous to those found in the piledwellings of the Swiss and Upper Austrian lakes.

The process of melting the copper in these crucibles differs in toto from that practised in any other country in modern times, but, as we shall see later, it is exactly the same as that by which prehistoric man melted copper and bronze for casting his rude implements of these metals. It is hardly necessary to point out that in melting metals at the present day the crucible is imbedded in the fuel of the furnace, the heat necessary for their fusion being applied to its exterior. In the Japanese process, however, the exterior of the crucible is not heated, but the fire is made in the crucible itself and above it. The furnace with the crucible in position is shown in figs. 8 and 9.

$\mathbf{a}$ is the furnace, as usual a simple hemispherical hole in the ground. In it is placed the crucible $\mathbf{b}$, the space $\mathbf{c}$ between the sides of the furnace and the crucible being filled with coarsely powdered charcoal. Lumps of ignited charcoal are then put into the interior of the crucible and also piled up over it in the form of a low conical heap. The bellows $\mathbf{f}$ are started, pieces of copper are placed on the heap above the blast-pipe $\mathbf{d}$, and more charcoal is piled over them. The copper, when it reaches the intensely heated zone in front of the blast, gradually melts and trickles through the charcoal to the bottom of the crucible, where it accumulates. During its exposure to the air of the blast, several impurities are oxidised, forming a slag which is removed from time to time. When sufficient copper has been melted the crucible is lifted out of the furnace and its contents poured into moulds in the manner shown in fig. $10 .^{\mathrm{a}}$

The exterior of the crucible when taken out of the furnace is barely red hot. The effects of the high temperature are only visible on the upper part of the rim and in its interior, exactly what we find in the crucibles and melting spoons of prehistoric man.

- The moulds are of canvas, set in a large trough of hot water, and the copper is poured into them in a full stream through the water. 
Should the copper ore treated by the Japanese smelting process contain foreign metals, such as tin, arsenic, antimony, nickel and lead, the resulting copper will contain these metals in varying proportions according to the quantities of each which may have been present in the ore. Similarly, and for the same

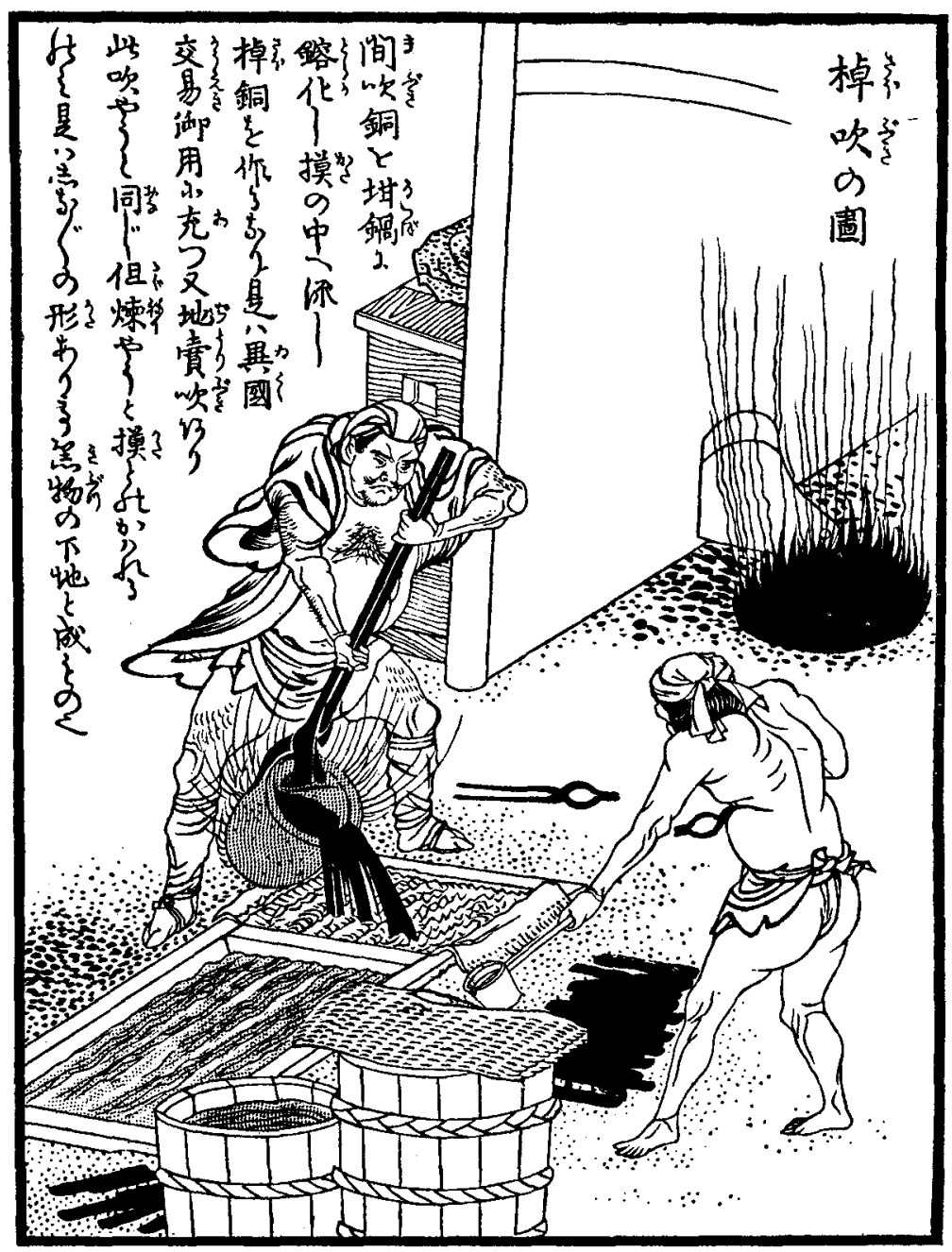

Fig. 10. Casting copper in Japan.

reason, these metals are also found in the celts and other early objects of copper in Europe. In the table which follows I have arranged, for the sake of comparison, some analyses of Japanese copper from various provinces and of early copper objects from different parts of Europe. 
More examples could have been inserted, but those given are representative types, and are amply sufficient to show how closely analogous in composition the Japanese copper is to that of prehistoric times in Europe. The average percentage of copper is practically identical in both series, the nature of the impurities only being different, and the proportions of sulphur higher in the Japanese examples. Such a comparison is not without value, as, although it does not prove with certainty that the process and furnace used by prehistoric man in Europe was identical with those of Japan, yet it affords some evidence in favour of the view that they were not very widely different.

Analyses of ancient European Copper Objects and of modern Japanese Copper.

\begin{tabular}{|c|c|c|c|c|c|c|c|c|c|c|}
\hline & Copper. & Tin. & Lead. & Iron. & Arsenic. & Antimony. & Nickel. & Silver. & Sulphur. & Analyst. \\
\hline Hammer, Siebenburgen & $98 \cdot 73$ & - & - & 0.84 & - & $0 \cdot 05$ & 0.03 & - & $0 \cdot 35$ & Helm.a \\
\hline Flat axe, Posen & $99 \cdot 16$ & 0.05 & $0 \cdot 03$ & $0 \cdot 08$ & 0.51 & - & 002 & - & 0.03 & Fischer." \\
\hline Kettle, Mycenæ & $98 \cdot 47$ & $0 \cdot 09$ & 0.16 & 0.03 & 0.83 & - & $0 \cdot 19$ & 0.013 & 一 & Ward. $^{c}$ (Contained \\
\hline Spear head, Cyprus & $98 \cdot 398$ & - & - & 0.729 & trace. & - & $0 \cdot 153$ & - & $0 \cdot 305$ & $\begin{array}{l}\text { Flight. } \\
\text { gold } 0.305 \text { per cent.) }\end{array}$ \\
\hline Flat ixe, ${ }^{e}$ Ireland & $98 \cdot 67$ & 0.05 & $0 \cdot 07$ & $0 \cdot 14$ & $0 \cdot 77$ & nil. & trace. & $0 \cdot 12$ & trace. & Gowland. \\
\hline Rough disc, Bungo, Japan & 98.86 & nil. & 0.02 & $0 \cdot 11$ & trace. & nil. & 0.25 & $0 \cdot 06$ & 0.70 & Gowland. \\
\hline$" \quad, \quad$ Ugo, Japan & $98 \cdot 41$ & " & $0 \cdot 46$ & 0.75 & " & $"$ & - & 0.018 & $0 \cdot 36$ & Gowland. \\
\hline $\begin{array}{c}\text { " cake, Rikuchū, } \\
\text { Japan } \\
\text { " disc, Yamato, } \\
\text { Japan }\end{array}$ & $\begin{array}{l}98 \cdot 80 \\
98 \cdot 94\end{array}$ & $\eta$ & $\begin{array}{r}038 \\
\text { trace. }\end{array}$ & $0 \cdot 10$ & $\begin{array}{r}0.08 \\
\text { trace. }\end{array}$ & $\begin{array}{l}\text { trace. } \\
\text { nil. }\end{array}$ & 一 & $\begin{array}{l}\text { U.011 } \\
\text { trace. }\end{array}$ & $0 \cdot 39$ & $\begin{array}{l}\text { Gowland. (Contained } \\
\text { gold } 0.081 \text { per cent.) } \\
\text { Gowland. }\end{array}$ \\
\hline
\end{tabular}

\section{Early Copper Smelting in Europe.}

Guided by the facts derived from the study of the primitive method of copper-smelting in Japan, I will now endeavour to trace, as far as is possible, the origin and development of the smelting of copper in early times in Europe.

Unfortunately the remains left by the very earliest smelters are so scanty and imperfect that it is difficult to interpret their indications as accurately as we can

a Zeitschrift für Ethnologie, xxvii. 23. $\quad$ b Zeitschrift für Ethnologie, xxix, 239.

c Schliemann, Mycence and Tiryus, 376. d Journal of the Chemical Society, xli. 143.

e British Museum.

VOL. EVI.

$2 \mathrm{R}$ 
those of the débris and objects of slightly later times. Nevertheless, when they are viewed in the light of Japanese metallurgy, it is not difficult to deduce from them the nature of the furnace and process by which copper was obtained in the earliest times.

It will, I think, be universally admitted that when neolithic man first became acquainted with metal his metallurgical operations must have been conducted on a very small scale indeed; and we may also not unreasonably assume, from what we know of the evolutions of customs and industrial arts among primitive races, that his first smelting-furnace would differ but little, if at all, from his domestic fire.

The first metallurgical furnace was hence, most probably, a similar fire on the ground, the fuel and embers being more or less kept together by a circle of rough stones. Below the fire a shallow depression would be scraped for the reception of the metal.

As bellows of any kind were probably unknown, the natural wind would be utilised for increasing the heat of the fire to the point necessary for the reduction of the ore.

With this simple arrangement, aided by only a moderate wind blowing through the crevices between the stones, copper could be smelted without difficulty from the easily reducible oxidised surface ores of which I have already spoken.

In the course of time, as the metal gradually came into more and more extensive use, and the demand for it increased, the fire would be made larger and the cavity in the ground deepened.

The work of smelting would, however, be intermittent and limited in character. It would be, to a very great extent, dependent on the wind, as on calm days the operation would be much retarded by the deficient temperature. Some kind of bellows or appliance for producing an artificial blast of air was then invented and employed, the hole in the ground was made larger to contain the increased quantity of metal produced, and a form of furnace such as we now see in Japan, in its most advanced form, was gradually evolved.

No remains of these early smelting furnaces have yet been discovered, but this is not surprising, as doubtless they were of very small size, and had little of an enduring character about them; in fact, no parts, excepting the clay linings of their hearths, which could long resist the destructive action of the weather. These too were undoubtedly often destroyed in later times and smelted for the copper with which they were saturated.

Heaps of slag alone remain to mark their sites and to furnish us with a 
record of the methods of their workers. Often, too, it is difficult to say from the character and composition of these slags whether they are the results of prehistoric smelting or belong to times within the historic period, as the primitive furnaces and methods may have survived in some localities until a comparatively late period. We have then to rely solely on the conditions under which they occur, and on the remains, such as stone hammers, and tools of stone and deer horn associated with them, for the evidence needed for the determination of their approximate date. Should the remains of the early furnaces ever be discovered, I venture to predict that they will be found to be of the forms I have just described.

In a later period than that of the Transition from stone to metal, in the true Bronze Age, valuable evidence is afforded respecting the size and shape of the smelting furnaces of that date by the lumps of copper which have been found from time to time in the founders' hoards. The peculiar columnar structure which all these pieces exhibit on their fractured faces can only be obtained by breaking the metal just when it is on the point of solidification. This proves incontestably that the mode in which the copper had been removed from the furnace is identical with that practised in Korea, as already described (page 280). Thus, the molten metal, after the fire and slag had been raked from off its surface, was carefully watched until the point of solidification had been almost reached. The cakes were then quickly pulled out of the furnace and broken up into lumps on a large stone.

The dimensions and shape of these cakes, which can be ascertained from the curvature of the lumps, will hence give us the size and shape of the furnace in which they were produced.

These lumps are generally fragments of a rough plano-convex disc-shaped mass of metal not much exceeding $1 \frac{1}{2}$ inches in thickness at its thickest part. The diameter of the disc can only be approximately ascertained, but usually cannot have been less than 8 inches or greater than 12 inches.

This would indicate that the smelting furnace in which copper was then extracted from its ores was a shallow conical or hemispherical hole, such as I have already described, not much exceeding, if at all, 1 foot in diameter at its widest part, and in other respects resembling the primitive furnace of Japan.

An important centre of metallurgical industry of very early age has been revealed to us by the explorations of the distinguished archæologist, Dr. Much, ${ }^{\mathbf{a}}$

a M. Much, Die Kupferzeit in Europa, 249 et seq.

$2 \mathrm{R} 2$ 
of Vienna, on the Mitterberg Alp, near Bischofshofen (Salzburg), and within reach of the lake dwellers of the Mondsee and the Attersee in Upper Austria.

Here rude mining excavations and heaps of slag testify to the extent of the workings, which seem to have been carried on until about the middle of the seventh century. Whilst the occurrence in their proximity of stone implements and pottery having close affinities with those found in the pile dwellings of the Mondsee proves, in a conclusive manner, that the earliest mining and smelting operations at least were conducted by people contemporaneous with the inhabitants of these lake dwellings.

Dr. Much's exploration of these remains on the Mitterberg are the most complete that have been made of any prehistoric copper smelting works, yet there are many points in connection with them which are still obscure and require further investigation. I had not read his account of these explorations until after I had written my description of prehistoric copper smelting in Europe, as deduced from my investigations of the primitive processes and furnaces employed in Japan; I am hence gratified to find that, as far as these explorations go, they support my views, and thus endorse the value of the study of comparative metallurgy for the elucidation of the smelting processes and appliances of remote times.

No remains of the furnaces of the earliest workers appear to have been discovered, and the furnace which Dr. Much was fortunate in unearthing is obviously of a later period; it is, however, of the greatest possible interest, as it is the only ancient copper furnace yet found in Europe.

The furnace consisted of a square space enclosed by walls of broken stone and lined with loam. Its internal dimensions were $19 \frac{1}{2}$ inches by $19 \frac{1}{2}$ inches, and although its depth is not stated it must have been somewhat less than this.

The shape of its interior, when completely lined and ready for working, cannot have been rectangular, but must have been originally hemispherical or conical, otherwise its metallic contents could not be removed. I may say that at the present day all copper furnaces, even if their walls are rectangular, always have their refractory linings of a conical form at the base.

The lumps of slag near only weighed about twenty-nine and a half pounds to forty-seven and a half pounds.

Dr. Much mentions no apertures in the sides of the furnace for the introduction of the blast or the removal of the metal; if there had been such they could not have escaped his observation. I am hence of the opinion that the furnace is exactly similar to the Japanese smelting furnace, excepting that it was built above the ground level; and was worked in the same way, that is, 
the blast was led into it over its upper edge, and its contents, both of slag and copper, were removed from its open mouth as is the Japanese practice. Respecting the date of this furnace and more than twenty others of which Dr. Much discovered the sites, I think there can be no question that it is far removed from the period of the lake-dwelling people of the early Bronze Age, and approaches rather to the time when the mines were abandoned on the invasion of the Slavs in the seventh century.

Furnaces of such capacity as it mean the production of copper in very much larger quantities than is borne out by the number of metal implements and objects found in the Upper Austrian lakes.

That copper was smelted in Britain before Roman times is incontestably proved by the discoveries of hammers and implements of stone in the ancient copper mines near Llandudno, and in Cardiganshire and Anglesea.

It is, too, scarcely possible to conceive of the smelting of tin in Cornwall, and the intercourse which arose in consequence between the Cornish Britons and the highly civilised peoples of the Mediterranean, without arriving at the conclusion that the ores of copper which occur in that part of England in immediate proximity to those of tin must also have been smelted there several centuries before our era.

In Roman times copper smelting seems to have been vigorously carried on, and among all the varied remains which are representative of the Roman metallurgist in Britain, few are of greater interest than the cakes of copper which have been found in North Wales and Anglesea.

A typical specimen of these cakes which is now in the British Museum is represented in fig. 11. It was found together with two others at Amlwch, Parys Mountain, Anglesea. Its weight is twenty-six pounds twelve ounces, and its dimensions are: diameter, $11 \frac{5}{8}$ inches; thickness, about $1 \frac{1}{2}$ inch. On its upper surface it has been stamped when hot with a circular stamp, bearing the letters IVLS.

Another, also worthy of note, is one which was found, according to Pennant," near Caerhen, the ancient Conovium, only a few miles distant from the old mines near Llandudno. Its weight is about forty-two pounds and its dimensions are: diameter, 11 inches; thickness in the middle, $2 \frac{3}{4}$ inches. On the upper surface is a deep concave-impression with the words SOCIO ROM E, and across this is impressed obliquely in smaller letters the inscription NATSOL.

a Pennant, A Tour in Wales (1784), 65. The locality for this cake is disputed by the Hon. W. Owen Stanley (Archceological Jonrnal, xxx. 62), who states that it was found near Aberfau, Anglesea, in the neighbourhood of which place are also ancient mines. 

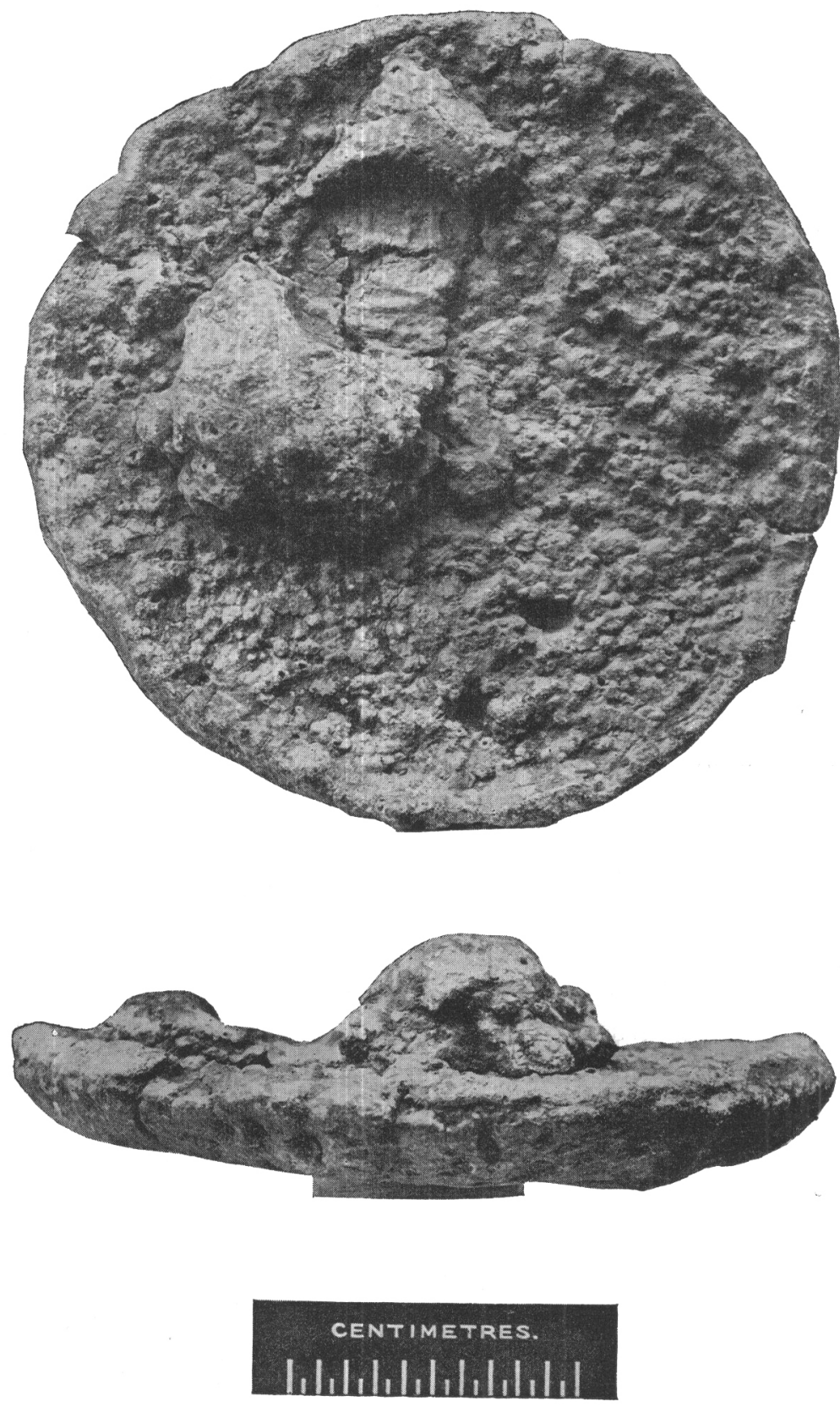

Fig. 11. Roman cake of copper, found at AmIweh, Anglesea. British Museum.a

a I am indebted to the courtesy of our Secrefary, Mr. C. H. Read, Keeper of British and Mediæval Antiquities, for permission to photograph this cake of copper and also the objects represented in Figs. 13 and 14. 
These cakes bear in their form and characters an unmistakable record of their history. They, as well as several others which have been found, are of the same shape, circular, with a slightly convex base and a rough flat top. The surface of the top is extremely irregular, being covered with vesicular-rounded bosses and having one large crater-like prominence near the centre.

This peculiar structure is not due to the sluggish flow of the last portion of the metal, as has been stated by some writers, but has been produced in the following manner: During the gradual solidification of the cakes sulphurous acid gas has been freely evolved, and in escaping has thrown up the greater part of the surface of the copper into the rough vesicular bosses, and the portions last fluid into the large crater-like humps. This phenomenon is technically termed "rising," and is seen daily in all copper works.

These characters are of extreme importance, as they show us not only how the cakes were made, but also that they were obtained by smelting ores consisting largely, if not wholly, of pyrites or sulphides. Unfortunately, no traces of the furnaces have been discovered. Yet, from the evidence afforded by the cakes themselves, and guided by the primitive smelting operations of Japan, I may venture, without being accused of temerity, to reconstruct the old Roman furnace, and explain the manner in which it was worked. If we assume that each cake was the result of a single smelting operation, an assumption the truth of which is hardly open to doubt, the dimensions of the furnace cannot have been more than about 18 inches in diameter and 12 inches in depth. Its interior must have been a conical or hemispherical cavity, lined with a mixture of clay and charcoal, and either sunk in the ground similar to the Japanese furnace, or, if raised above it, surrounded by a low wall of stones like those on the Mitterberg Alp. It was undoubtedly worked by an artificial blast of air, from a bellows or blowingmachine of some kind, which was conveyed into the furnace by one or more blast-pipes which rested on the edge of the cavity. The ore, which consisted chiefly of copper pyrites, would be prepared for smelting by expelling the greater part of its sulphur by calcining or "burning" it in heaps piled up over faggots of wood. The calcined ore was then gradually charged into the furnace in alternate layers with charcoal, just as described (page 277), until sufficient had been added to produce when smelted one of these cakes of copper. When the whole was melted the last slag was removed and the molten copper laded into a cavity in the ground near the furnace. The metal was certainly not tapped out of the furnace, as the operation of tapping copper is one of considerable difficulty, and would, moreover, have been impossible in such furnaces without greatly injuring if not destroying them. 
The absence of Roman buildings and of Roman stonework or brickwork of any kind at the old mines where these cakes were produced is very curious, and would almost seem to indicate that the mining and smelting were carried on chiefly by the Britons themselves and by their own methods. What Roman intercourse and supervision there may have been appears to have affected these methods but little, excepting that the mining excavations are more regular and the smelting operations are carried on on a more extensive scale than in earlier times.

Thus far I have only dealt with the methods by which the metal copper was extracted from its ores. There still remains for our consideration the mode in which it was cast into useful forms. Few memorials of the art of the prehistoric copper founder in Europe are more interesting and suggestive than the rude clay vessels in which he melted or alloyed his copper, and the simple moulds of stone in which he cast the metal into the forms of his primitive implements. Specimens both entire and fragmentary have been discovered in considerable numbers and in widely distributed localities in Europe.

The earliest crucibles differ entirely both in form and composition from those of later and modern times. They are rude shallow vessels made of clay mixed with finely cut straw or grass (horse dung according to Keller, and cow dung according to Much). Their sides are so thick, and the clay of which they are composed is so fusible, that it was impossible to melt copper or bronze in them, by the application of heat externally, by embedding them in fuel as in a modern crucible furnace. The melting operation was hence performed by arranging the fire in and above them as follows: The crucible was placed in a shallow cavity in the ground in such a manner that its sides and base were completely protected from the action of the heat. A fire of charcoal was then piled up over it, and was urged by the wind or an artificial blast of air until the metal was melted, a method precisely analogous to, and arising from the same cause as, that practised in Japan (page 281). In consequence of this mode of heating, the lower parts of these vessels will, it is evident, bear little or no traces of the action of heat, although the upper edges and interior may exhibit a semi-fused vesicular structure, and this is precisely what we find in all these early crucibles.

Four of the most important types of these crucibles are illustrated in fig. 12. No. 3 is a form of somewhat wide distribution in the remains representing the early Bronze Age in the pile dwellings of Switzerland, the Danubian basin, and Ireland. ${ }^{a}$

a Localities in which crucibles of this form have been found: Robenhausen (Lake Pfäftikon, Switzerland); Mannedorf (Lake Zurich); Niederwyl, near Frauenfeld (Switzerland) ; the Mondsee (Upper Austria); Laibach Moor (Carniola); Loch Mourne and Loch Dowalton (Ireland). 
It consists of a shallow cup from which projects a handle, often furnished with a socket for the insertion of a stick, by which it was removed from the fire and its contents poured into a mould.

By some archæologists these are said to be ladles for lading molten metal from some larger receptacle, but if this were so they would show signs of having been exposed to a high temperature both within and without, whilst, as I have already pointed out, this is not so, only the interior and upper edges exhibiting marks of such exposure.

The specimen illustrated was found among the remains of the pile dwellings of the Mondsee (Upper Austria).

Another form is the shallow oval dish (No. 1), which is of much rarer occurrence than the former. It also was found in the Mondsee. It is difficult to speak

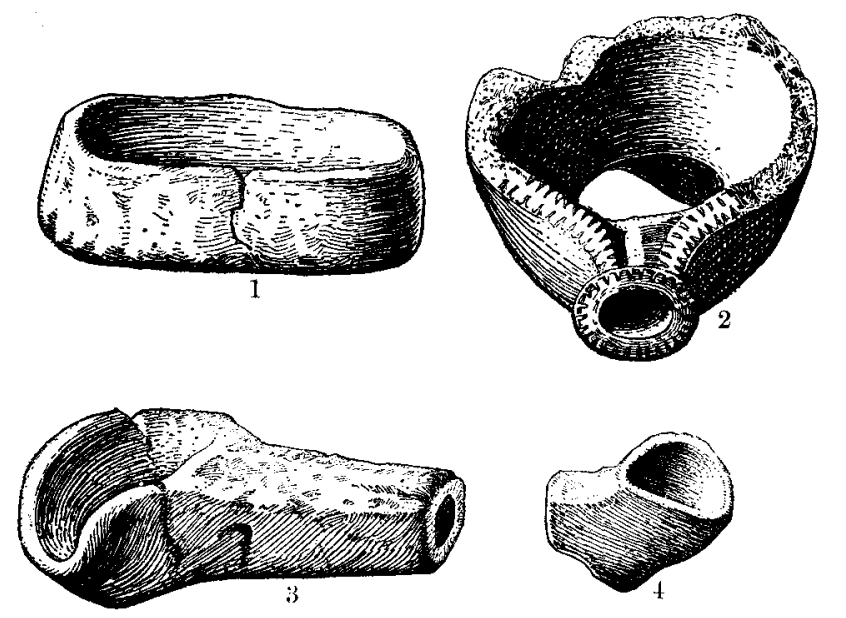

Fig. 12. Early forms of crucibles.

( $\frac{1}{4}$ linear.)

with certainty about the use of these shallow oval vessels. They can hardly have been used for making castings, as they could not be held by tongs, or by any means known to me, for pouring their contents into a mould. It is, however, quite possible that they were employed in a rude refining process, by which part of the impurities in the crude copper obtained by smelting were removed by allowing the air to act on the surface of the metal; or, it may be, they are the vessels in which the founder made his alloy by melting together broken implements, or copper, with tin or its ore.

The clay vessel (No. 2) was found among the débris of pile dwellings on Laibach Moor (Carniola). It is said to be a crucible, and it may probably have been so used, but I think this is open to doubt.

VOL, LVI. 
That represented by No. 4 was obtained from the remains of a crannog in Lough Mourne, Antrim. It is of special interest, as it is of precisely the same type as those of the Mondsee and of the pile-dwellings of the Swiss lakes.

Another form of crucible is a small shallow circular dish (fig. 13), several of which were discovered by the brothers Siret, together with copper and bronze implements, and moulds and other objects of stone, in their explorations in Murcia and Almeria, in the south-east of Spain.

The specimen shown in the figure was found with others in a stone receptacle among ancient dwellings at El Argar. a Its upper edges and interior alone show signs of exposure to an intense heat, so that in it also the metal was melted

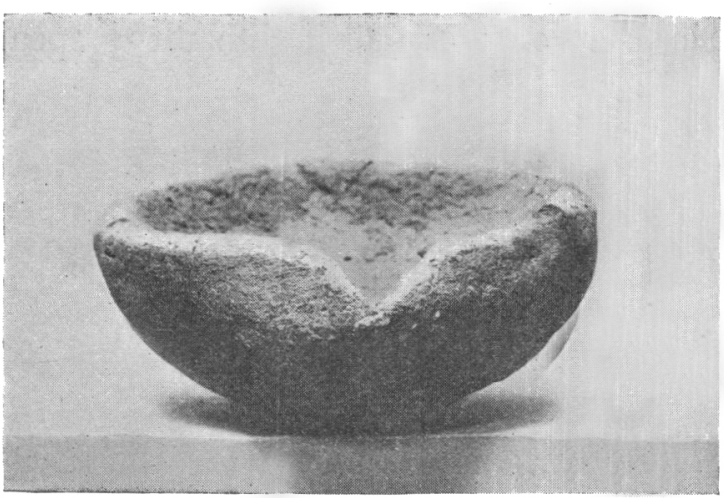

A.

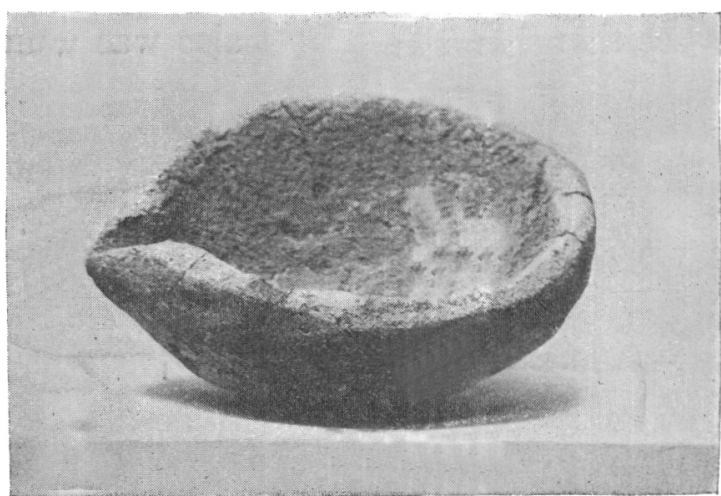

B.

Fig. 13. A and B. Clay crucible found at El Argar. British Museum.

in the manner described above. Its dimensions are as follows : external diameter, $4 \cdot 5$ inches ; diameter of cavity, $3 \cdot 7$ inches; depth of cavity, $1 \cdot 1$ inch.

The very small capacity of these crucibles, as well as of the ladle-like forms, is worthy of note. Few can have held more metal than would suffice for the casting of a single flat axe. This is, however, not altogether surprising if we remember that they are the appliances of that remote time in the founders' art when metals were scarce and costly, and metallic weapons and implements were only beginning to replace those of stone.

Perhaps even more interesting relics of early metallurgy than the crucibles are the moulds by which neolithic man copied the forms of his stone axes and other objects in copper and bronze.

Those used by the earliest workers in metal were of clay or stone. Moulds of

a Siret, Les premiers Ages du Métal dans le Sud-est de l'Espagne, pl. 27. 
sand or loam were undoubtedly of later times, as there are considerable mechanical difficulties in preparing them so that they may be suitable for casting copper, whereas the production of clay and stone moulds would present no difficulties to men who had already acquired considerable skill in the manufacture of pottery, and were experts in the working of stone. As moulds of the first-mentioned material, clay, are of a less enduring nature than those of stone, but few have been preserved, although they were doubtless employed in the very earliest times. In almost all the regions of Europe occupied by men of the early metal age moulds of stone have been found. The earliest are of the class known as open moulds, viz. those which consist merely of cavities of the outline and depth corresponding with the form and size necessary for the object to be cast, hollowed

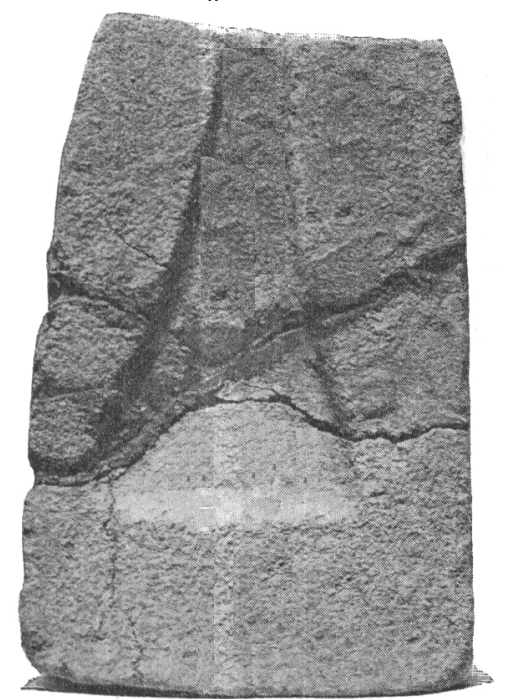

Fig. 14. Stone mould found at E Argar. British Museum. in the surface of the stone, which were simply filled with the metal. Of these fig. 14 is a characteristic example. It was found together with others and the crucible, fig. 13, at El Argar, and is intended for the casting of a flat axe, about 5.5 inches long, with a cutting edge of 3 inches.

Those open moulds continued long in use, as it is only in moulds of this kind that sound castings of copper could be made. A flat celt is hence the only form of axe which can be cast of pure copper. Socketed celts and palstaves, which require closed moulds, can only be cast of copper when it is alloyed with, or contains as impurities, not less than about one per cent. of tin or arsenic, or a somewhat larger quantity of lead, or when it is saturated with oxide, otherwise they would be unsound and unserviceable implements, full of cavities or blowholes.

The bearing of this on the theory of a universal Copper Age I hope to discuss in another paper. For the same reason I omit a description of the more complex forms of moulds of the true Bronze Age. 


\section{TIN.}

\section{The Metallurgy of Tin in Japan.}

Although tin ore ${ }^{a}$ is found and worked in Japan in several localities, there is but one ancient mine in the country.

It is situated at Taniyama, in the province of Satsuma. The excavations of the old miners here are of a most extensive character, the hill sides in places

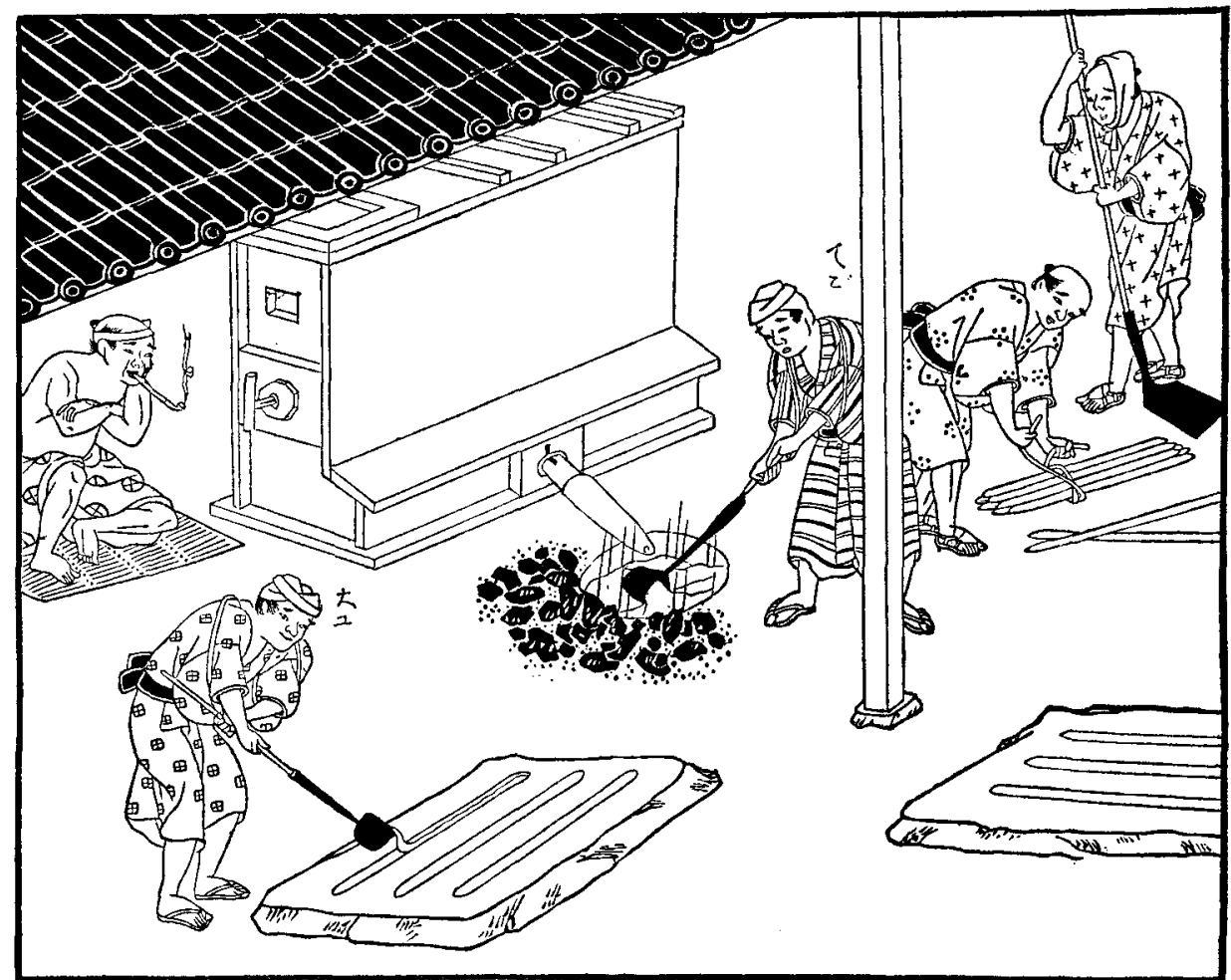

Fig. 15. Tin smelting. Casting the metal into bars, Japan.

being literally honeycombed with their burrows, indicating the production in past times of large quantities of the metal. No remains, however, have been found to give any clue to the date of the earliest workings. But, whatever may have been their date, the processes and appliances of the early smelters could not have been more primitive than those I found in use when I visited the mine in 1883.

a Cassiterite, the oxide of tin, is practically the only ore of the metal. 
The ore was roughly broken up by hammers on stone anvils, then reduced to a coarse powder with the pounders used for decorticating rice (described in page $273)$; the mortars being large blocks of stone with roughly hollowed cavities.

It was finally ground in stone querns, and washed by women in a stream to remove the earthy matter and foreign minerals with which it was contaminated.

The furnace in which the ore was smelted is exactly the same as that used for copper ores (fig. 5), excepting that it is somewhat less in diameter. The ore was charged into it wet, in alternate layers with charcoal, and the process was conducted in precisely the same way as in smelting oxidised copper ores described (page 277). The tin obtained was laded out of the furnace into moulds of clay as shown in fig. 15.

The entire yield of each smelting charge was only about thirty pounds of metal, much being lost by volatilisation and in the slag.

Yet, with this primitive process and its rude appliances, the Satsuma smelters were producing tin at a cost not greater than that of the imported metal.

\section{The Metallurgy of Tin in Europe.}

With the exception of the north-west of Spain, Cornwall seems to have been the only region in Europe from which the ancient world derived large supplies of tin. In this part of Britain the conditions for the production of the metal were especially favourable; the ore was undoubtedly abundant, and subterranean mining operations were not required, as it was found, either at the surface of the ground, or at but little depth below it, disseminated through the old river gravels.

From the fusibility of tin and the comparative ease with which the ore is reduced, the metal must have been produced in Cornwall not very long after neolithic man settled there. And that this settlement took place in a very remote age is sufficiently proved by the megalithic monuments which are so numerous in that part of Britain.

It is, however, very surprising that no objects of tin have been found in association with either these early remains, or in the long barrows of a subsequent period in the not far distant counties of Wilts and Dorset, or under any other conditions in undoubted association with the stone implements of the Transition Period.

The earliest finds are only of the later Bronze Age.

The metal does not, however, lend itself to the manufacture of weapons of 
war or industrial tools, and hence may have been neglected. On the other hand, it is admirably adapted for simple ornaments, such as beads, rings, armlets, and the like, and was frequently so employed by the peoples of the pile dwellings in the lakes of Switzerland, France, and North Italy.

It is hence just possible that, although the metal may have been known, it may not have been regularly smelted from its ores, until a knowledge of its value as an object of barter had been ascertained by intercourse with the Mediterranean peoples through the medium of the tribes inhabiting the north-west and west of France.

No cakes or lumps of tin representing the earliest smelting of the ore have survived, but shallow holes in the ground, containing charcoal and ashes, sometimes intermingled with fragments of the metal, have been discovered from time to time near ancient workings in the old river gravels. These are the remains of the furnaces of a very early, if not perhaps the earliest period. Unfortunately neither sketches or measurements appear to have been made of them by their explorers, and the descriptions which have been recorded are imperfect and wanting in exactness.

The furnaces seem, however, to have generally been merely narrow shallow trenches in the ground. The smelting operation was one of the simplest kind, and must have been conducted in the following manner : The trench, having been first lined with clay, was filled with brushwood, above which small logs of wood were piled. A light was applied, and as soon as the logs were burning fiercely and the trench was full of glowing embers, small quantities of ore were thrown upon the top of the fire from time to time. More wood and ore were added, until the required amount of tin had accumulated in the trench. The fire was then raked away, and the tin laded out into a hole in the ground, or into a clay mould, near the furnace. Probably sometimes it was allowed to flow, as it was reduced, into a cavity at one end of the trench. The object of the trench, in addition to its use as a receptacle for the metal, was to hold a sufficient quantity of embers to reduce the portions of ore which had not been acted on in the upper part of the fire.

It is interesting to note here that a precisely similar mode of smelting continued to be used in Germany as late as the sixteenth century for the extraction of bismuth from its ores. The operations are very quaintly but clearly illustrated in fig. 16. G $\mathrm{G}$ are the shallow trenches, with faggots of wood piled over them, at the ends of which are cavities in the ground, $\mathrm{H} \mathrm{H} \mathrm{H}$, for receiving the metal. That a natural blast from the wind alone was used is indicated at $\mathrm{K}$ by the head of Boreas. 
The purity of the fragments of tin which have been found in these trenches indicates that the ore had been carefully washed free from impurities, also that it

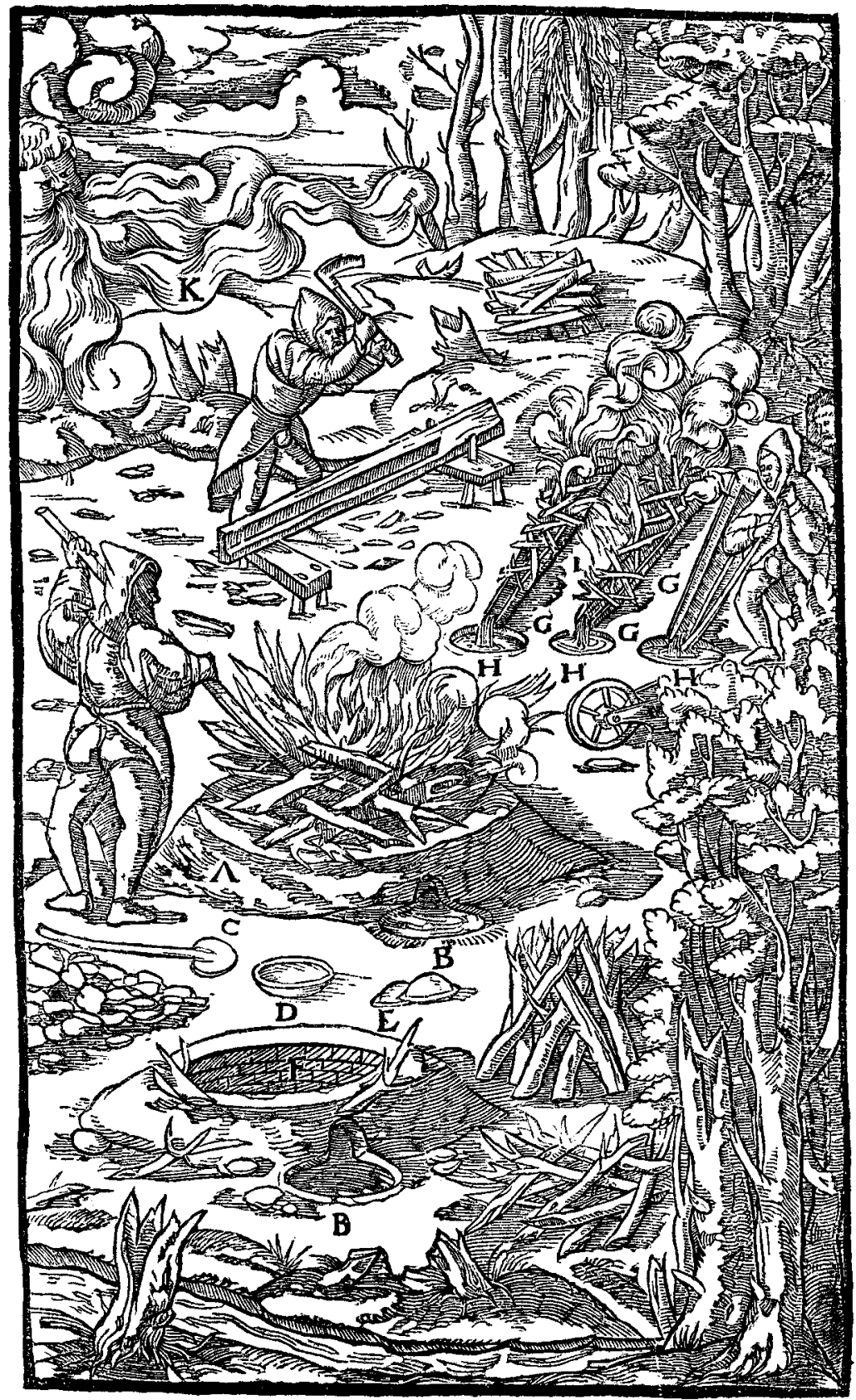

Fig. 16. Smelting ores of bismuth in the sixteenth century. ${ }^{a}$

The illustration is taken from Agricola, op. cit. 350 . 
had not been exposed to a very great heat, and hence, very probably, an artificial blast of air had not been employed.

This primitive method of smelting was not an efficient or economical one, as, on account of the high temperature required for the reduction of the ore, although tin itself is so fusible, much of it would often be left unreduced, and very large quantities of wood be consumed in proportion to the amount of the metal obtained. Its inefficiency was evidently soon apparent to the early smelter when the forests were becoming exhausted in the neighbourhood of his ore diggings and the demand for the metal for export increased. Charcoal seems then to have been substituted for wood as fuel, and the use of a bellows was introduced.

Pryce, a very shrewd observer, writing in 1778 , speaks of some remains found in his time as follows: "Some late discoveries, where the charcoal and dross of the metal have been found mixed together, have given us an idea of their process, which was to dig a hole in the ground and throw the Tin Ore on a charcoal fire, which probably was excited by a bellows. Agreeably to the simplicity of the times, no notion was entertained of confining the fire to make it act more forcibly on the substance to be smelted. The natural consequences of this were an undue consumption of fuel and a great loss in the produce of the ore, as the more stubborn parts would not give way to that degree of heat which by this method they were able to apply to them." "

He does not mention the shape of the holes; if they were hemispherical, or of the form of an inverted cone, both they and the process would be precisely similar to those I saw in operation in Japan (see page 295).

But the intercourse of the Britons with the traders from the more advanced races of the Mediterranean doubtless soon led to further modifications and improvements in their furnaces and mode of smelting. The shallow hole then became deeper, so as to "confine the fire," and was excavated near the edge of a bank of earth. The blast was no longer admitted over the edge of the cavity, but through an opening just above its base, the molten tin being allowed to flow out, as it was reduced, through a still lower hole.

The ruins of a furnace of this kind was found at Trereife, near some very extensive ancient excavations for tin ore. According to Le Grice," "the furnace was found in a high bank of clay. It was a cavity in the form of an inverted cone, 3 feet in diameter and 3 feet deep, with sides of hard clay only. At the bottom

a Pryce, Mineralogia Cornubiensis (London, 1778), 281.

b Transactions of the Royal Geological Society of Cornwall, vi. (1846), 43 et seq. 
was a flat stone, scarcely 1 foot in diameter, which had a border of small stones around it. On the stones were ashes. On one side of the bank was a small ravine by which, probably, the blast of air was conveyed by a bellows to the lower part of the furnace, and by which the smelted tin was discharged."

It is very unfortunate that this ruined furnace was not examined by a metallurgist, as there are several important points in the exploration of the remains which have been overlooked or disregarded.

The cavity does not, I think, represent the form or the size of the furnace, but is merely the hole left after the lining had been removed when the furnace was abandoned, as a furnace of its shape and dimensions could not possibly have been worked with the blowing appliances of the time. The remains are, however, evidently those of a small blast-furnace. From the diameter of the stone at the base, taken together with the small stones surrounding it, I think it must have been about 12 to 16 inches wide at that part. It was probably not more than about 2 feet 6 inches in diameter at the top, and extended about a foot or more above the present level of the ground. Its depth inside would then be about 4 feet. It would thus closely resemble, in internal form, the primitive furnace which only a few years ago was in use for smelting tin, without an artificial blast, in the remote district of Tras, in the heart of the mountain range that separates Pahang from Selangor in the Malay peninsula. ${ }^{\mathrm{a}}$

The ore was smelted in the usual way by charging it into the furnace in alternate layers with charcoal, and the metal was allowed to run out continuously into cavities in the ground, from which, in later times, it was laded into moulds of stone. From the construction of the furnace, and from the occurrence of Roman pottery and other remains in the débris of others resembling it, I think, there can be but little doubt that the furnaces in use during the period of the Roman occupation of Britain were of this form, although they had their origin in earlier times.

It is, however, very doubtful whether they were actually worked by the Romans themselves, as their sites and ruins are almost invariably found away from the coast, and there is an absence of sufficient evidence to show that the interior of Cornwall was ever completely subject to Roman rule. And the fact that there are no great military roads west of Exeter tends to indicate that the Britons then were at least semi-independent, although they undoubtedly carried on a friendly intercourse for the purpose of trade with the Roman settlements on the east and on the coast.

VOL. LVI.

a H. Louis in Mineral Industry (New York), v. 545.

\section{$2 \mathrm{~T}$}


With one doubtful exception, too, the blocks of tin which have been found do not, like similar finds of copper and lead, bear any Roman marks or stamped inscription. These blocks, many of which have been unearthed in various localities in the county, are generally called "Jews" "tin, an appellation which has perhaps arisen from the important control said to have been exercised by the Jews on the mining and smelting of tin during the reign of King John. They have, however, nothing to do with that people, neither have the furnaces already described. They belong to a very much earlier time.

One of the most interesting of these blocks (fig. 17) is that which was dredged up at St. Mawes, near the entrance of Falmouth Harbour. It is of the shape of an astragal (one of the cervical vertebræ), and weighs 158 pounds. ${ }^{n}$
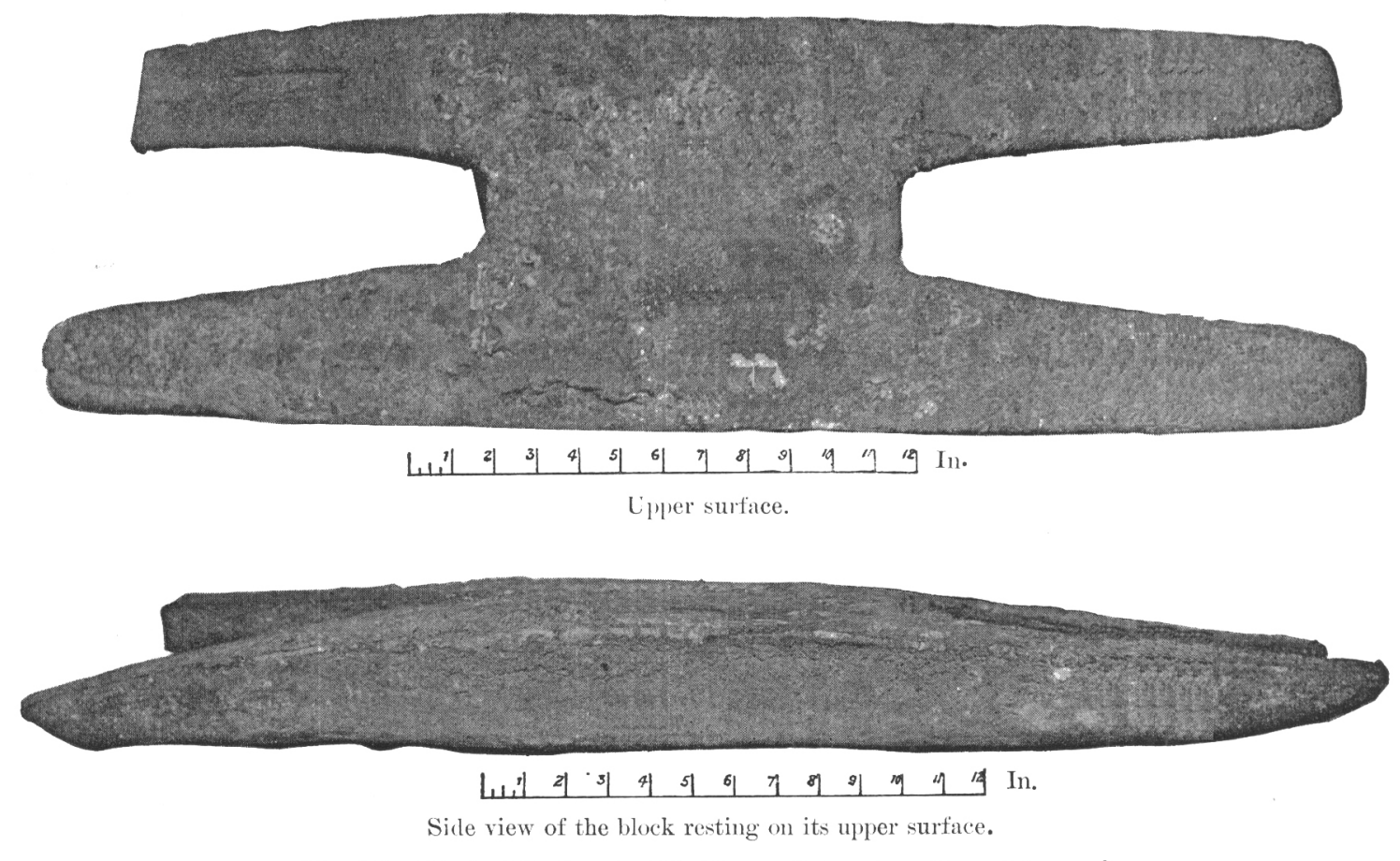

Fig. 17. Block of tin found at St. Mawe, Falmouth. Truro Museum. ${ }^{\mathrm{b}}$

Some ingenious conjectures as to the object of casting tin in this form are contained in the pamphlet by Sir Henry James mentioned in the footnote. He

"Note on the Block of Tin dredged up in Falmouth Harbour. By Col. Sir Henry James, R.E., Director of the Ordnance Survey. Jundon, 1863.

b Mr. R. A. Gregg, curator of the Museum of the Royal Institution of Cornwall, Truro, kindly superintended the preparation of the photographs from which this figure is taken. 
suggests that this shape was chosen in order to facilitate transport. Thus the curved base allowed such blocks to lie thwartwise in the bottom of a boat, whilst the double arms enabled them to be slung by ropes on each side of a packhorse.

This block has been ascribed to pre-Roman times. Most of the others are of more or less irregular forms, and vary in weight from a few ounces to about 80 pounds. They are generally coated with oxide of tin, the result of long exposure to the air and moisture.

One having an important bearing on the smelting process is a mass in which small rich pebbles of ore and fragments of charcoal are imbedded in metallic tin. It was evidently produced in a furnace of the form last described, when the working had become deranged owing most probably to a failure of the blowing appliances.

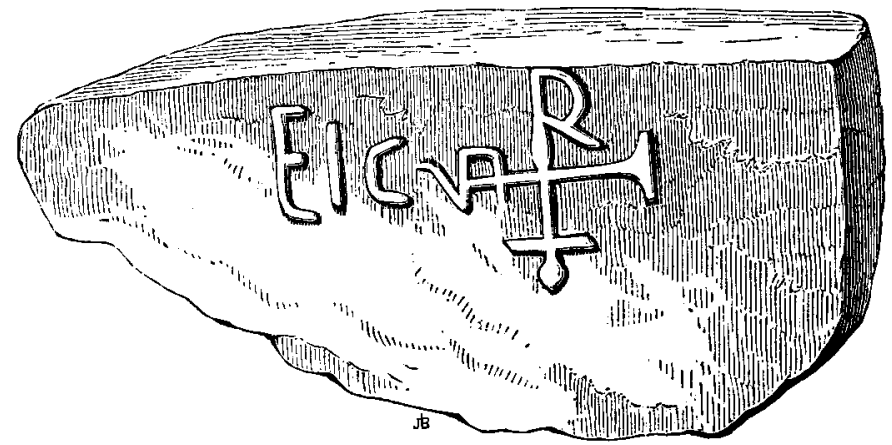

Fig. 18. Block of tin found at Trereife, Cornwall.*

A block which bears in relief the letters E I C, and also a curious device, is shown in fig. 18. According to Le Grice it was found at Trereife, on the top of the rubbish which filled the furnace described (page 298). Its weight is $29 \frac{1}{2}$ pounds, and the dimensions of the stamped face are: extreme length, 16 inches; extreme breadth, 8 inches. It is now in the Museum of the Penzance Antiquarian Society.

The next development of the tin smelting furnace was a simple but important one. It was constructed, without change of its internal form, above the surface of the ground instead of being imbedded in it. The date of this change is uncertain, but it was not, I think, effected until post-Roman times. It continued in use with but little alteration until about the end of the seventeenth century, when it was

- The accompanying woodcut has been kindly lent by the Royal Archaeological Institute. $2 \mathrm{~T} 2$ 
gradually abandoned in favour of the reverberatory furnace. I append in a footnote the description by Pryce ${ }^{\mathrm{a}}$ of one of these furnaces in use as late as the first half of the eighteenth century, as I think it may be taken as representing, with the exception of a few minor details, such as the "wrought-iron piece" through which the blast was admitted, and the "iron cramps," the ancient furnace first built above ground many centuries earlier.

\section{IRON.}

The discovery of the metal iron doubtless arose either from pieces of rich iron ore becoming accidentally imbedded in the domestic fire, the burning embers of which would easily reduce them to the metallic state, or, it may be, from primitive man, having already obtained the metal copper from certain stones, experimenting with others in the same manner in his rude furnace, when, if these consisted of iron ore, metallic iron would be produced.

In either case the heavy character of the lumps would attract his attention, and if, as he could not melt them, he attempted to fashion them by the modes then in vogue for the manufacture of stone implements, their malleable properties would at once be apparent.

The questions: Whether iron was, or was not, the first metal discovered by neolithic man, and: Whether it was known during the early part of the Bronze Age, have not yet been finally answered.

a Pryce, Mineralogia Cornubiensis (1778), 136. "The furnace itself for blowing the Tin is called the Castle on account of its strength, being of massive stones cramped together with Iron to endure the united force of fire and air. This fire is made with charcoal excited by two large bellows, which are worked by a water-wheel, the same as at the Iron forges. They are about eight feet long and two and a half wide at the broadest part. The fire place, or Castle, is about six feet perpendicular, two feet wide in the top part each way, and about fourteen inches in the bottom, all made of moorstone and clay, well cemented and cramped together. The pipe or nose of each bellows is fixed ten inches high from the bottom of the Castle in a large piece of wrought Iron, called the Hearth-Eye. The Tin and charcoal are laid in the castle, stratum super stratum, in such quantities as are thought proper; so that from eight to twelve hundredweight of Tin, by the consumption of eighteen to twenty-four sixty-gallon packs of charcoal, may be melted in a tide or twelve-hours' time. Those bellows are not only useful for igniting the charcoal, but they throw a steady and powerful air into the castle; which at the same time that it smelts the Tin, forces it out also through a hole at the bottom of the castle, about four inches high and one and a-half inches wide, into a moorstone trough six and a-half feet deep and one foot wide, called the float; whence it is laded into lesser troughs or molds." 
From the evidence derived from the finds of implements of copper in association with implements and objects of stone in several regions of Europe, it has been assumed that that metal was the earliest known. In some localities, however, where oxidised copper ores (cuprite or malachite) occur in admixture with tin ore (cassiterite), a bronze containing variable proportions of tin may have been produced contemporaneously with, or even earlier than, the pure metal.

There can be no doubt that the evidence advanced in support of this view seems at first sight to be formidable and overwhelming. It is, however, my duty to point out here that archæologists and metallurgists, speaking generally, are by no means in agreement as regards this priority of discovery which is claimed for copper and bronze. The former, for the most part, adopt the view that the order of discovery of the metals was, first, copper, then bronze, and, lastly, iron; and they support this by arguments based on the relative number and forms of the objects of the first two metals which have been unearthed together with objects of stone, and on the rarity of finds of iron objects with similar accompaniments, or under conditions which indicate an equally remote antiquity. A few, less happily, have been influenced in their deductions by the erroneous assumption that the fusion of iron is necessary in order to extract it from its ores, and that, in the earliest times, the high temperature required could not have been obtained by the aid of any appliances then known.

The metallurgists admit the rarity of the occurrence of iron objects in the remote period of the early Bronze Age, but state in explanation that iron is so easily oxidised by the influence of the air and moisture, occasionally even passing into solution and becoming diffused in the soil, that it is almost an impossibility for any objects of the metal to have been preserved under the conditions to which the stone and bronze objects of most finds have been exposed.

The erroneous belief that fusion is necessary for the extraction of iron is evidently founded on the modern method of iron smelting, a method only dating in Europe from the seventeenth century, and in ignorance of the fact that before that time it was the aim of the iron workers to produce only wrought iron, and the metal was hence always obtained in the form of a solid mass, and not as molten cast-iron.

The distinguished metallurgist, the late Dr. Percy, in a passage in his monumental work on Iron and Steel, ${ }^{,}$so ably and tersely states the metallurgical view of this question, that I will quote it in extenso. He says: "From suitable ore, of

^ Dr. Percy, Metallurgy, Iron and Steel (London, 1864), 873. 
which abundant and readily accessible supplies exist in various localities, nothing more easy can be conceived than the extraction of malleable iron. Of all metallurgical processes it may be regarded as amongst the most simple. Thus, if a lump of red or brown hæmatite be heated for a few hours in a charcoal fire, well surrounded by or imbedded in the fuel, it will be more or less completely reduced, so as to admit of being easily forged at a red heat into a bar of iron. The primitive method of extracting good malleable iron directly from the ore, which is still practised in India and Africa, requires a degree of skill far inferior to that implied in the manufacture of bronze. From metallurgical considerations, therefore, it is reasonable to suppose that the so-called Age of Iron would have preceded the Age of Bronze."

The opinions of Ledebur, the eminent professor of metallurgy at the School of Mines of Freiberg (Saxony), agree with those of Percy. He states: " On admettait généralement, autrefois, qu'un âge de bronze avait précédé la découverte du fer; quelques archéologues maintiennent cette opinion. Il paraît, cependant, démontré aujourd'hui que, dans les contrées où se rencontrait un minérai de fer pur, ce métal a été connu avant le bronze et même avant le cuivre. En effet, pour obtenir du fer par le procédé le plus simple, encore en usage chez beaucoup de peuples sauvages, il faut des appareils moins compliqués et une bien moindre somme de travail que pour extraire le cuivre de la plupart de ses minerais."

Dr. Beck, an able metallurgist, the distinguished historian of the metal, in his masterly work Die Geschichte des Eisens, enumerates the examples in which iron has actually been found in association with objects of the early Bronze and the late Stone Ages, and gives a brief account of the most important. ${ }^{b}$ From these he concludes that iron was the first useful metal (nutzmetall) which was known to the dwellers in northern Europe. The evidence furnished by these examples is undoubtedly of a weighty character, yet, I think, the question of the priority or contemporaneity of the discovery and use of iron, as compared with the discovery and use of copper and bronze, or vice versa, should, at the present stage of the inquiry, be considered undecided; as nothing is a greater hindrance or more destructive to scientific investigation and research than the acceptance of a theory, or supposed fact, the truth of which is not supported by proofs of an absolutely conclusive character, and especially so if such theory or supposed fact is propounded or accepted by men eminent in the subject concerned.

a A. Ledebur, Manuel de la Métallurgie du Fer (Paris, 1895), 6.

b Dr. Ludwig Beck, Die Geschichte des Eisens (Braunschweig, 1892), i. 593-596. 
From the foregoing remarks it will be evident how extremely important it is that in all archæological explorations every fragment of iron oxide (rust) should be very carefully examined and its occurrence noted. In some of the dolmens of Japan which I explored shapeless masses of iron oxide, which could easily have been mistaken for lumps of iron ore, alone were found; in others, however, more favourable conditions for the preservation of iron had prevailed, and, although the objects consisted chiefly of rust, their shapes were sufficiently preserved to enable me in many cases to decide what these shapeless masses in the former had originally been.

\section{The Extraction of Iron from its Ores in Japan.}

The metal iron, according to the early philosophy of the Chinese, is a product of the masculine principle of nature, and therefore possesses hardness and tenacity. It appears to have been known to that ancient people from very remote times, as early as or perhaps much earlier than 1000 B.c.

It was not, however, known in Japan until much later times. The semimythical and legendary records of the Japanese point to Korea as the source from which the metal was first obtained by them; but the abundant occurrence in Japan of an iron ore easily reducible in the most primitive furnaces, together with the intercourse maintained with China through Korea, must have resulted in its production in the country itself at a very early date. That it was worked in Japan certainly in the first centuries of our era, and possibly earlier, is proved by the numerous and widely distributed examples of iron-work, such as swords, arrow-heads, horse-bits, etc. which have been found in the ancient burial-mounds, dolmens, and rock-hewn tombs.

The ore from which all the metal was obtained, until very recent times, was magnetic iron sand, which occurs disseminated in a soft decomposed granitic rock in Izumo, Iwami, Aki, and the adjacent provinces in the western part of the main island.

It accumulates in certain parts of the beds of streams and torrents after heavy floods and rains, and is then collected by farmers at times when they are not occupied with field work. In ancient times this is said to have sufficed for the production of all the iron needed, but at present the decomposed rock is excavated and thrown into the streams, on the bottom of which straw mats have been spread; the earthy matter is then washed away by the current and the rich ore is left behind on the mats. 
The process by which iron and steel is still produced from this sand is one of special metallurgical and archæological interest, as in it we see, in actual operation, a form of furnace and a method of smelting which have survived from prehistoric times. The furnace, according to the traditions of the smelters, was originally very much shorter than at present, and had not more than two or four holes for the entrance of the blast, but in principle and construction it presented no difference. And here we may note, in passing, a curious feature in the development of this furnace, viz. its extension in a lateral direction only, as it is in striking contrast with the vertical development of the primitive iron furnace in Europe.

In the rudeness and simplicity of its construction, and in its temporary character, the Japanese iron furnace which still survives in use in several districts, and in which, until about thirty years ago, the whole of the iron needed in the country was produced, has no parallel in any region of the world.

Fig. 19,

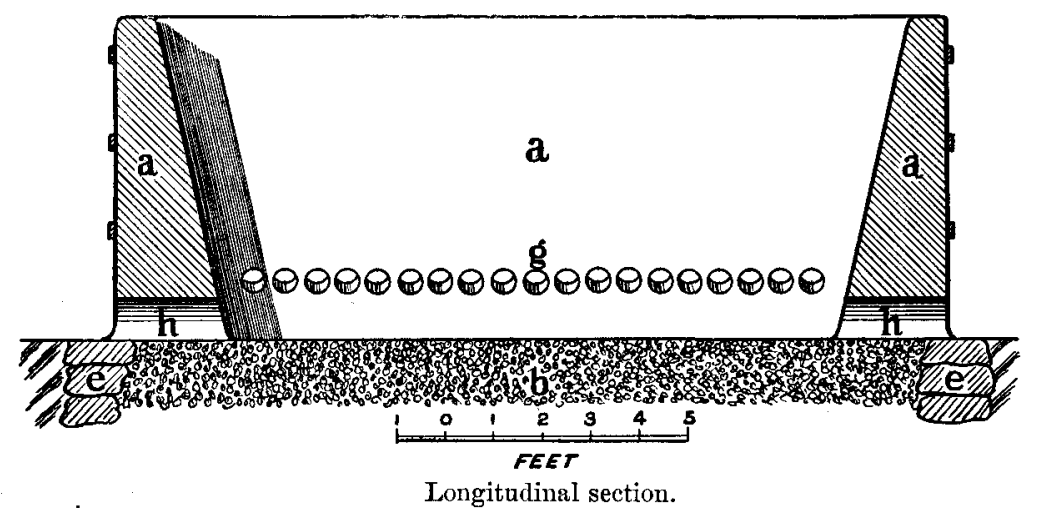

Fig. 20

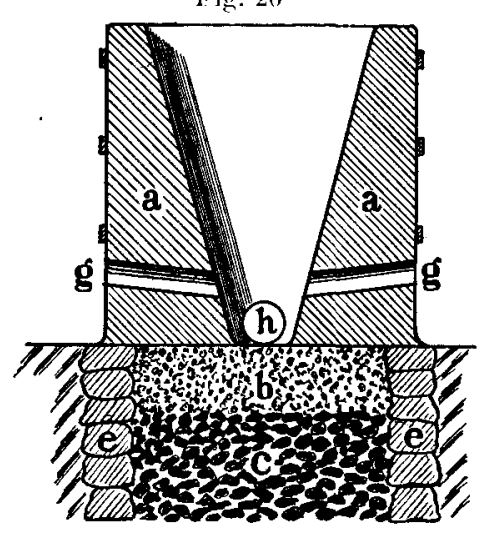

Transverse section.

Figs. 19 and 20. Blast-furnace for the extraction of iron from its ores. Japan.

Even the earliest furnaces of Europe, so far as we can infer from their imperfect vestiges which are left to us, were of a more advanced type than it. It is built entirely of clay without even an enclosing wall of rough stones.

A specially remarkable peculiarity of this furnace which is seen in no other known to me, excepting one described by Mungo Park as in use in West Africa, ${ }^{\mathbf{a}}$ is that it only lasts for a single operation, as its walls are rapidly corroded and destroyed by the high temperature of the process, and moreover, the parts which have resisted the fire have to be completely pulled down in order to obtain the iron and steel which have been produced. Hence an entirely new furnace has to be built for each operation.

a Mungo Park, Travels in the Interior Districts of Africa (London, 1799), 283-5. 
The furnace is shown in sectional elevations in figs. 19 and 20. Its construction presents no difficulties whatever, as it is simply a V-shaped trough, with walls of a common clay, a material which occurs everywhere in the districts of the decomposed granitic rock which contains the ore.

The substructure of coarse charcoal c, shown in fig. 20, an improvement of recent introduction, is intended to prevent the lower parts of the trough from chilling. Usually the foundation was simply a bed of dry clay.

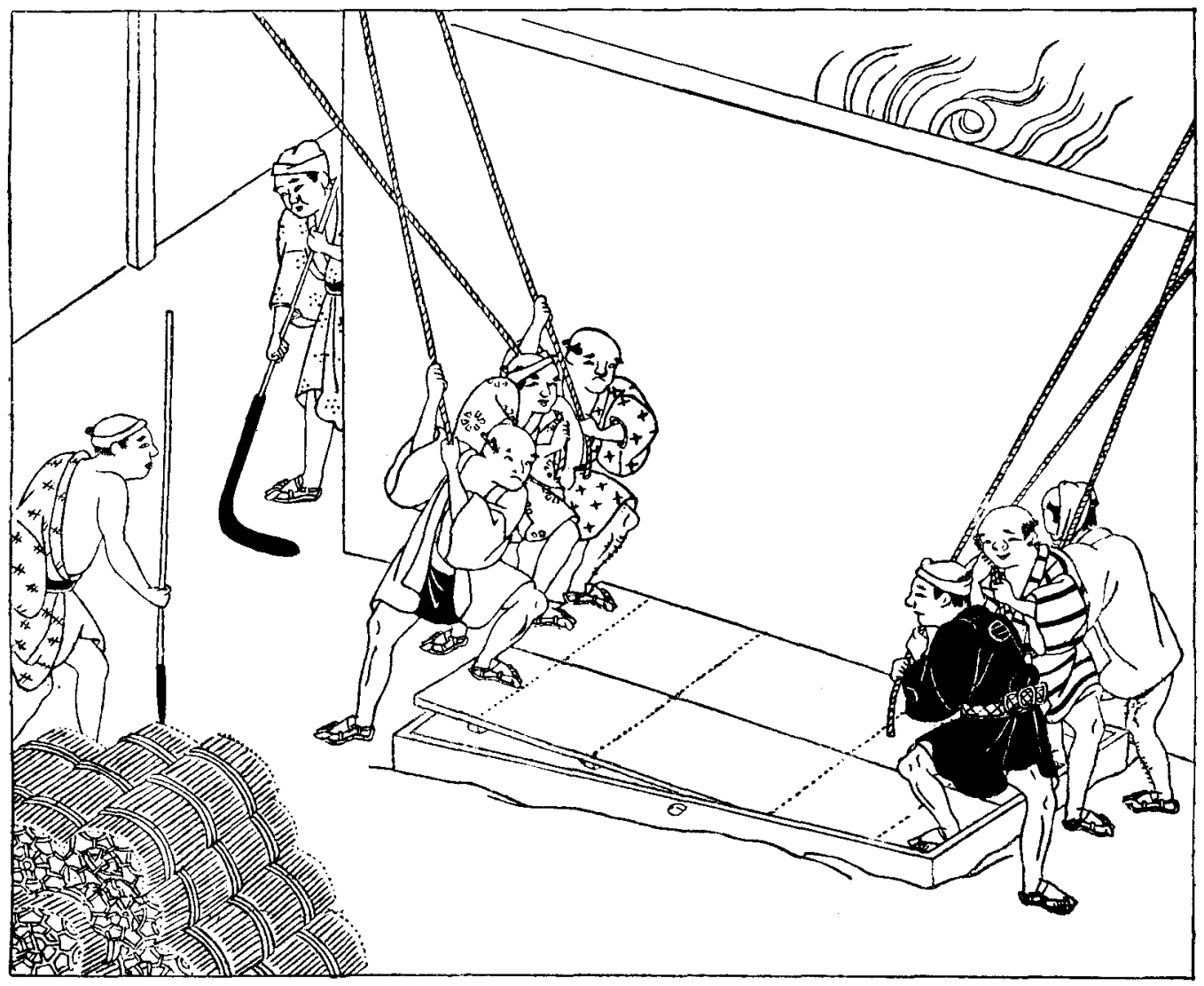

Fig. 21. Working the blowing machine (Tatara) at a blast-furnace for the extraction of iron from its ores.
Japan.

The chief parts of the furnace are:

aa. Walls of clay.

gg. Holes for the introduction of the blast.

$h h$. Apertures for the escape of slag and of any cast iron which migh be formed.

VOL. LVI. 
The blast is supplied from two blowing machines called tatara. This blowing machine is a very ingenious and effective appliance. It consists of two air chambers over which a pressure board is fitted on an axle. To this pressure board a rocking motion is given by the workers stepping alternately on and off either end, as shown in fig. 21 ; the air is thus compressed and a blast produced.

The operation for the extraction of iron from its ores in this Japanese furnace is conducted as follows: As soon as the walls have been built and dried, the trough-like cavity is filled with charcoal and the blowing machine started. When the charcoal has become thoroughly ignited a layer of iron sand is spread over it, and upon this more charcoal. As the charge sinks, owing to the reduction of the ore and the combustion of the fuel, more iron sand and charcoal are added, and these additions are continued for about sixty hours. By the end of that time the sides of the furnace have been so much destroyed by the intense heat and the fluxing action of the ore that the operation can be no longer continued. The end walls are then broken down and the fire raked out. Large masses of steel and wrought iron are then seen to be adhering to the side walls, and sometimes a long lump of cast iron in the bottom of the trough. These are then removed by means of levers and bars, and when cold are broken up with hammers, chisels, and other mechanical appliances. A new furnace is at once built on the old site and is ready for smelting in about twenty-four hours.

The masses of metal detached from the side walls are very irregular mixtures of iron and steel, parts consist of the former and parts of the latter, so that weapons or tools forged from one part will be of steel and from another part of soft iron. Hence arises the variable character of very ancient weapons, such, for example, as those found at Khorsabad ${ }^{\text {a }}$ by M. Place, and the spears and swords of the early Iron Age in Denmark, all of which were doubtless made from iron extracted from its ore by a method similar to the above, before the invention of a special process of steel manufacture. The cast iron and impure parts of the steel are converted into wrought iron in a small furnace resembling a Catalan forge.

When it is desired to produce cast iron in these furnaces the pressure of the blast and the proportion of charcoal are both increased. The iron is not cast into pigs but is merely run out of the furnace on to the level ground, where it is broken up with heavy logs of wood.

This process, notwithstanding its primitive character and the rudeness of its furnace and appliances, was capable of performing excellent work. It

a Perrot and Chipiez, Chaldea, ii. 311. 
produced without difficulty an iron purer by far than our larger furnaces and more complicated methods can yield, and it furnished the steel for the magnificent blades of the famous swords of old Japan. It is still carried on with advantage, and, for certain purposes of the native smith, competes successfully with British iron. But the end of its days is fast approaching, and before many years elapse it will disappear and be remembered only as a relic of a bygone age.

\section{The Extraction of Iron from its Ores in Europe.}

That the metal iron was extracted from its ores in Europe at a very early period indeed is demonstrated, in a conclusive manner, by the discoveries of many sites on which prehistoric ironworkers had plied their craft.

A consideration of each of these sites would require more space than is available in this paper. I will hence confine my attention to those which are of the most importance, either from their extent or from the nature of the remains which they have yielded to explorers.

Unfortunately, the most diligent search has so far failed to reveal to us any vestiges, sufficiently definite or intelligible in their indications, to enable me to say with absolute precision what was the form of the furnace first used by prehistoric man for the extraction of iron; or to recover, even in a fragmentary form, the history of his first efforts in the metallurgy of that metal. A comparative study, however, of the primitive furnaces in Japan, which I have just described, and of others in Southern Europe and elsewhere, affords most valuable data for the solution of these problems, and aids us greatly in tracing the iron furnace of Europe back to its primitive form, and in depicting the various stages of development through which it must have passed in its evolution. If we apply to the consideration of this subject the same methods of inquiry which were employed in dealing with the early metallurgy of copper, it will, I think, be evident that, broadly speaking, the origin and development of the furnace were as follows: If the discovery of copper preceded that of iron, the furnace for the extraction of iron would, as I have already stated, undoubtedly have been based on that which was in use for the smelting of that metal (page 284). If, on the other hand, iron was first discovered, it would have had its origin in the ordinary domestic fire, and in the first stage of its development it would consist simply of a shallow hole in the ground, which, as metallurgical skill increased, would be deepened and widened until it attained about the same

$$
2 \text { U } 2
$$


dimensions as the Japanese copper furnace (page 277), and, like it, would be worked by means of a blast introduced over its edge.

In several countries, as we shall see later, the furnace and the primitive methods of working it never passed beyond this stage. In some cases, it is true, the cavity in the ground assumes the form of a similar cavity above the surface, of larger capacity, and enclosed more or less completely by a wall of stones or lumps of ore, yet, nevertheless, it is still practically the primitive furnace of the early workers.

The second stage in the development of the primitive furnace is principally seen in the region to the north-east of the Adriatic and in Central Europe. It is one of great importance and far-reaching results, and is chiefly characterised by a change in the mode of introducing the blast. From this change, however, there certainly arose an alteration in the form of the furnace itself and in the manner of constructing it. The furnace cavity was hence made deeper, and was excavated just within the perpendicular face of a low bank through which an opening was made into its interior for the removal of the iron. The blast which formerly was introduced at the top was now admitted at the bottom, either through the same opening by which the iron was removed, or through one or more apertures specially made for the purpose.

The furnace as now developed possessed several important advantages, one of the chief being that the process for the extraction of iron could be carried on continuously in it, whereas this was not possible in the earlier forms. At this stage, strange to say, its development is arrested, and although its construction and the materials of which it may be built vary from time to time, yet in its essential character it remains practically unchanged during several centuries before our era, and until long after the fall of the Roman Empire.

Before proceeding to consider the remains found on the ancient smelting sites, which illustrate the furnace in the various stages of its development, it will be advisable to review briefly the process by which iron was produced in it.

The actual process for the extraction of iron from its ores in Europe, in fact, in all countries in early times, was everywhere practically the same; it was only in the furnaces and appliances that differences occurred. It was too one of the simplest in the whole range of metallurgy whatever form of furnace was used. The fuel was charcoal, and this was placed in the furnace, and sometimes also piled above it, in alternate layers with the iron ore. The temperature of the fire was raised to the point necessary for the reduction of the ore to the metallic state 
by a blowing appliance of some kind, although in some districts it almost seems as if the natural force of the wind alone was employed in the earliest furnaces.

It is important to remember here that the metal was never melted, but was always obtained in the form of a solid mass of malleable iron, which sometimes was mixed with steel. Cast iron may occasionally have been produced in the furnaces representing the second stage of development (page 310), when the intensity of the blast may have been increased from accidental causes, and there was at the same time an excess of charcoal present. But as, on account of its brittleness, it could

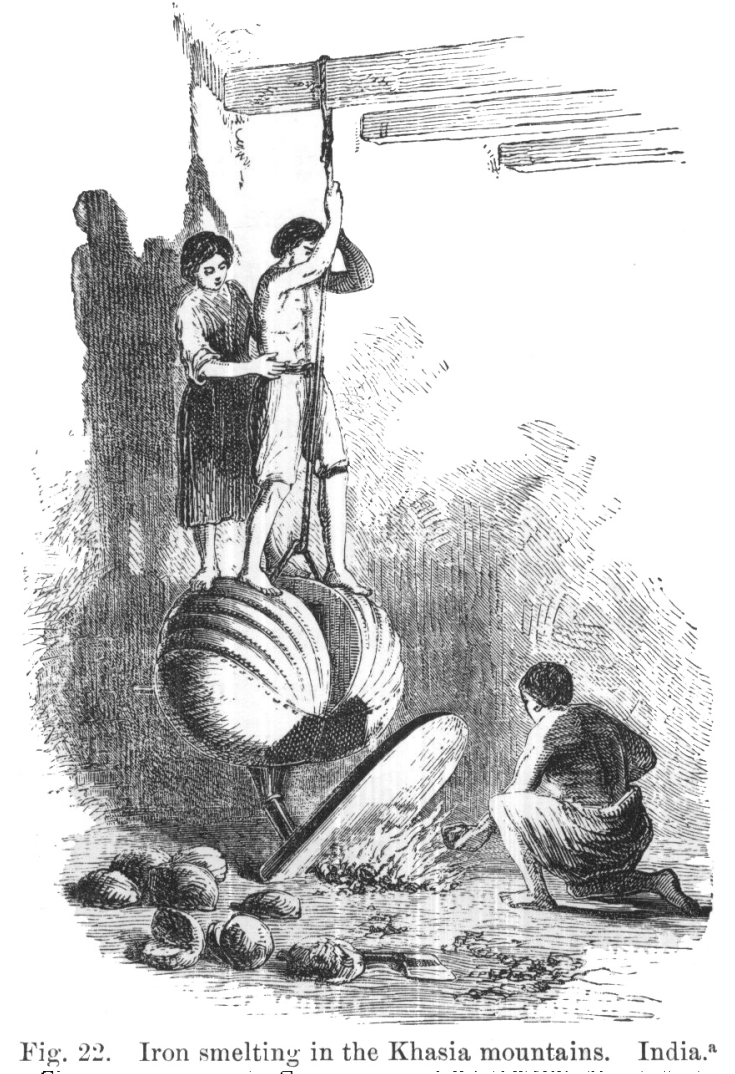

not be utilised, it was, in Europe, apparently returned to the furnace with the next charge, as no specimens of early date have ever been found.

No remains of the most primitive form of furnace, for example, the shallow hole scraped in the ground, have been, or are likely to be, discovered in Europe, on account of its diminutive size and non-enduring character. It was, however, not extinct in India about fifty years ago, as it was then seen in operation in the Khasia mountains by Dr. Hooker, as shown in fig. 22. "The smelting," Dr.

a This illustration has been kindly lent by Messrs. Murray. 
Hooker states, "is carried on in charcoal fires. The fire is kindled on one side of an upright stone (like the head-stone of a grave), with a small arched hole close to the ground. Near this hole the bellows are suspended, and a bamboo tube from each of its compartments meets in a larger one, by which the draught is directed under the hole in the stone to the fire. The ore is run into lumps as large as two fists, with a rugged surface; these lumps are afterwards cleft nearly in two to show their purity." a

Not differing greatly from the furnace and blowing appliances of the Khasia Mountains is that illustrated on page 312 of Wilkinson's Ancient Egyptians, vol. ii. The figure represents a metallurgical process as depicted on a tomb bearing the name of Thothmes III. (reigned 1503-1449 B.c.).

From the four bellows employed it would seem that the process is the extraction of iron from its ore, as the blast from these would be very much in excess of that required for any other metallurgical operation. The furnace is evidently a mere cavity in the ground.

Of a slightly more advanced type is the native furnace of Kordofan (Soudan), which it is important not to pass over in silence on account of its analogies with

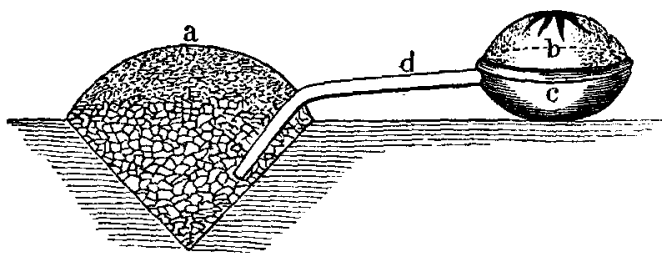

Fig. 23. Furnace and bellows used in the extraction of iron from its ores. Kordofan. the early iron furnace not only of the Egyptians but also of the Etruscans. In fig. 23 is represented the furnace and bellows which were seen at work by Russegger ${ }^{\mathrm{D}}$ in the north of Kordofan about fifty-seven years ago. From this it is clear that they are practically identical with those of early Egyptian times.

The dimensions of this furnace were 12-14 inches in diameter and about the same in depth, which agree very closely with the Japanese furnace for copper, tin, lead, and to which it is similar in form. The process, according to Russegger, consisted in charging the ore and charcoal into the furnace in alternate layers, urging the combustion of the latter to the utmost power of the bellows for about ten hours; the fire was then raked away, and the mass in the furnace cavity allowed to cool. This was then removed, the upper slag. broken off, and the lower part, consisting of pieces of iron mixed with rich slag,

a Himalayan Journals (London, 1854), ii. 310, quoted in Percy's Metallurgy, Iron and Steel, 262-264.

b Russegger, Reise in Ägypten, Nubien und Ostsudan (Stuttgart, 1844), II. 2, p. 286 et seq. 
was put back into the same furnace and heated for two hours, when a mass of malleable iron was obtained.

The furnace which was employed by the Etruscans at a very early date, both in the island of Elba and on the mainland, is very closely allied to the furnace of Kordofan, the only difference, in fact, being that it was constructed on, and not below, the surface of the ground.

At Populonia, where are vast accumulations of ancient iron slags, the remains of one were found by Simonin, ${ }^{a}$ and near it a heap of rich Elban ore. This furnace consisted of a low wall of rough sandstone blocks enclosing a cavity in which the ore had been reduced with charcoal as fuel.

A process similar to that practised by that ancient people still survives in Corsica. ${ }^{b}$ It closely resembles that of Kordofan, and like it consists of two stages, in the first of which the ore is partly reduced and agglomerated, and in the second the agglomerated mass is again heated in the same furnace, when a lump of iron is obtained.

That the Etruscan furnace had its origin in Egypt does not at present admit of absolute proof, yet it can undoubtedly be regarded as representing the first stage in the development of the old furnace of the monuments.

This leads us to the important and difficult question: Was it from Egypt that Europe derived the first knowledge of iron? From metallurgical considerations only we would certainly be led to the inference that the Etruscans had obtained their knowledge of the method of extracting the metal from that source.

Closely analagous to the ancient furnace of the Etruscans, in fact, in its early form identical with it, is the Catalan furnace of the Pyrenean region of the north of Spain and the south of France, which has been in use there from very remote times up to our own day. That it had an independent origin in that locality cannot be reasonably maintained, and I think we may hold, on the strongest grounds of probability, that it was introduced from the Elban region during some part of the Etruscan Age. In connection with this it is worthy of note, that in the Mediterranean region of Europe, west of the Appenines, no other type of iron furnace has ever been in use until modern times. In other parts of Europe it was also employed to a certain extent, but was not usually the most important form.

The determination of the kind of furnace used in early Britain is, strange to say, a matter of considerable difficulty. As, although there is a variety of proofs

a L. Simonin, "De l'exploitation des mines et de la metallurgie en Toscana." Annales des mines, T. xiv. 1859, p. 557,565 .

b For a description of the Corsican process, see Percy, Metallurgy, Iron and Steel, 315-319. 
amply sufficient to demonstrate that iron was produced in the country several centuries before the coming of the Romans, few remains of metallurgical operations exist which can be ascribed with certainty to that time.

The ancient slags are of the same nature and composition as those produced in the Roman period, and although they do not contain Roman remains neither have they been found in direct association with British objects.

Of the furnaces, too, of Roman times the vestiges are of the most fragmentary and imperfect character. No débris of any furnace, sufficiently perfect to enable us to deduce from it its original form, has yet been unearthed, notwithstanding that the enormous quantities of slags intermingled with Roman pottery, etc. which occur in the Forest of Dean and the Weald, in addition to other evidence, testify to the extensive prosecution of the iron industry during the Roman occupation.

This is very surprising in view of the numerous discoveries of iron furnaces of still earlier date in various parts of Europe. In connection with this, however, it must be remembered that the sites on which most of these have been found are in remote uncultivated districts, and have been left undisturbed since they were abandoned many centuries ago, conditions especially favourable for their preservation. The furnaces, too, are chiefly those representing the second stage of development (page 310), being circular shafts built in a bank of earth.

Now, had the furnaces in Britain been of this type, which, as we shall see later, is of a remote age in the Danubian basin and in Central Europe, some would, undoubtedly, have been preserved.

Roman pottery kilns built in like manner and of less substantial construction are of frequent occurrence in England; therefore I think that the iron furnaces, had they been of the shaft furnace form, would certainly not all have perished.

I am hence of the opinion that the iron furnaces of Britain before Roman times, and long afterwards, were simple low hearths resembling the Catalan furnace. The fuel was charcoal, and the "bloom" of iron was taken out from the top of the furnace.

This view is also borne out by the character of the slags. These are more vesicular and less perfectly fused than those obtained in the furnaces with circular shafts.

Respecting the source whence Britain first derived the furnace and the method for the extraction of iron from its ores, I think we may reasonably conclude from the foregoing considerations that it was the Mediterranean region of Europe, either the eastern Pyrenees or north-west Italy. It may, however, be advanced that the earliest iron furnace of the ancient Britons originated from the 
furnace which they employed so successfully in the extraction of tin, and in which iron ores could certainly be reduced. Yet I think the former view is the more rational one, supported as it is by the fact that intercourse between the Mediterranean peoples and the Britons was carried on long anterior to the working of iron in the country.

Two of the earliest sites in Europe for the extraction of iron from its ores are situated in the Danubian region, in the district which in Roman times was known as the province of Noricum, and within reach of the people represented by the metallic remains found in the famous graveyard of Hallstadt. One is in Carinthia in the upper basin of the Drave, the other in Styria on the Mur, both important tributaries of the Danube.

It will be sufficient for the purpose of this paper to consider the former site only. This I have selected as it has been more carefully explored than the other, and the remains which have been found on it are typical, and represent fairly the character of the metallurgical operations which were carried on when the metal iron was first applied to practical uses in this region of Europe.

How far the old people of this district of Noricum preceded the Etruscans in the production of iron in Europe is a question about which much might be said, but more evidence, which further research alone can yield, is required for its satisfactory solution. The former, I have endeavoured to show, seem to have derived their furnace and process, through Egypt, from the iron districts situated on the west of the Upper Nile. The Norici, on the other hand, I think there are strong reasons for believing, were influenced by Asiatic methods of metallurgy almost, if not quite, from the very beginning of their attempts in the production of iron.

The shaft form of furnace which was used by them was certainly in use in China at a time when probably iron was not known in Europe; and in India we still find it in one of its primitive forms. It is hence by no means improbable that a knowledge of it reached Noricum and Central Europe from Asia via the north of the Caspian and Black Seas and the Danube. The shaft furnace, however, may perhaps have had another origin. It may have been the result of the development in loco of the primitive hole-in-the-ground furnace, yet, if so, it is very singular that it should be found only north of the Alps and in Southern Europe on the east of the Appenines.

The most important sites of the ironworkers in Carinthia are in the neighbourhood of Hüttenberg. They are indicated by heaps of slags and the débris of furnaces which are without doubt of a very early age, long prior to the occupation

VOL. LVI.

$2 \mathrm{x}$ 
of Noricum by the Romans. They have been carefully explored by Münichsdörfer, from whose report ${ }^{2}$ the following notes are extracted.

The earliest furnaces, of which many were met with, are vertical holes, excavated near the face of a steep bank, with a lateral hole near their base, to which the wind was admitted by a horizontal channel in the front of the bank, lined with stone.

According to Münichsdörfer, the blast for these was obtained from the natural wind alone. Others, of later form, consist of small cylindrical shafts, 3 to 4 feet high, also built in banks of earth, to which an artificial blast from some blowing appliance was admitted through short clay twyers or tubes. Several of these twyers which were found had their front ends fused by the heat of the furnace, thus indicating the use to which they had been put.

In this district, as well as in those of Vordernberg (Styria) and Radmannsdorf (Carniola), where also are very extensive evidences of the ancient metallurgy of iron, the Romans in later times actively carried on the extraction and manufacture of the metal.

Far to the north of these, but still in the Danubian region, we have another seat of the ancient iron industry. This extends from the lower grounds of Moravia, near Brunn, to the range of hills which separate that country from Bohemia.

Scattered over the slopes of these hills are numerous heaps of iron slag and remains of rude diggings for ore. In one of the latter Dr. Wankel, who explored these sites, found some iron picks and also a broken stone hammer. In his report $^{\mathrm{b}}$ he does not mention any relics of furnaces on the range. But near Brunn he discovered the site of a prehistoric smelting-works which seems to have been of considerable importance. Yet his account of the remains is so full of fancy and hypothesis that it is impossible to conjecture either the form of the furnace or the nature of the process which they represent.

A district rich in remains of early furnaces, of somewhat later date perhaps, but not of less importance than those of the Danubian region, is the Bernese Jura, on the north-west of Lake Neuchâtel (Switzerland). It is besides of special interest as it doubtless afforded the iron which the lake-dwellers of La Tène fashioned into weapons and other objects with such marvellous skill.

a Münichsdörfer, Der Hüttenberger Errzberg, 10 et seq.

b Dr. H. Wankel, Prähistorische Eisenschmelz- und Schmiedestätten (Wien, 1879), 29 et seq. Quoted by Beck, op. cit. 628 . 
The whole range of the Swiss Jura has been explored with great care and ability by A. Quiquerez, a mining engineer specially qualified for the work by his technological knowledge. His investigations, which extended over several years, have revealed to us the sites of more than four hundred iron mines and metallurgical works; two hundred and thirty of which he had explored himself. All

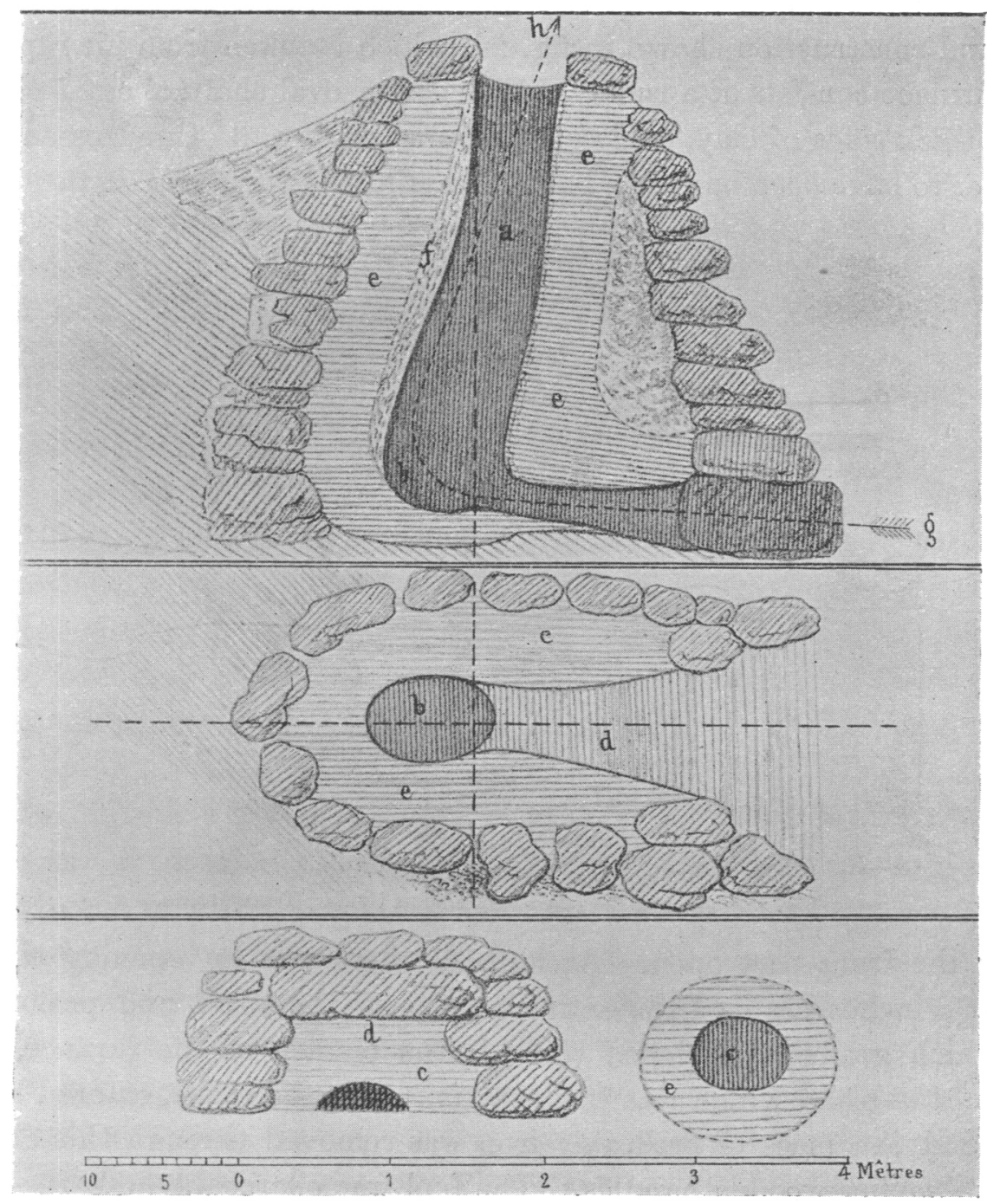

Fig. 24. Ancient iron furnace of the Jura, as restored by Quiquerez.

the remains are by no means of the same age, but the separation of the earliest from those of a later time is not an insuperable task.

Ten of the sites are those of rude mining excavations to obtain the iron ore, evidently of a very early period, as in them were found tools of flint and jasper $2 \times 2$ 
only. On twelve were débris of furnaces associated with stone implements and Gaulish pottery. Thirtynnine yielded relics of other furnaces all of pre-Roman date. These early remains were most abundant in the forests of the uninhabited valleys between the spurs of the range.

From a careful study and comparison of the vestiges of several furnaces, Quiquerez concludes, and I think not unreasonably, that they were originally of the form and construction shown in fig. 24, which is taken from his report."

The furnace consists of a rudely cylindrical or oval shaft, about 7 feet 6 inches high, with thick sides of clay, enclosed within a rough wall of undressed stones. It seems either to have been built in a bank of earth or to have had earth piled around

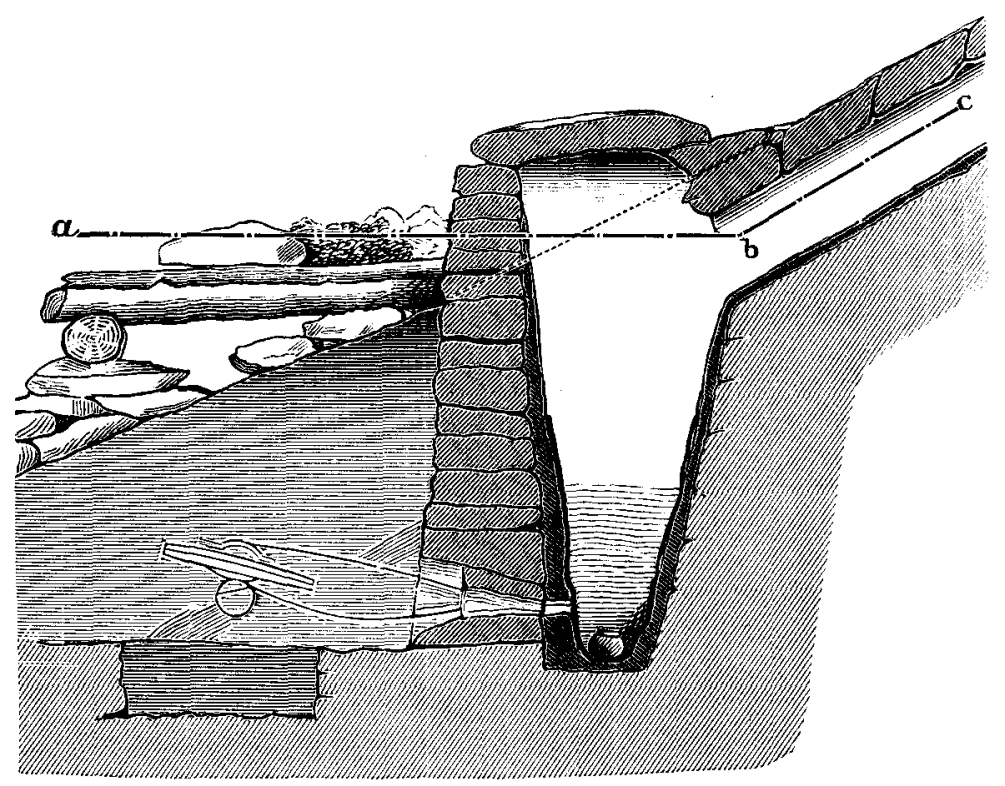

Fig. 25. Ancient blast-furnace found at Gyalar, Transylvania.

it, leaving the front part open. At its base there was an opening on the front side, about 8 inches high, of the entire breadth of the shaft, and prolonged into a channel which gradually widened towards the outside of the furnace. Through the channel the blast, which was from the natural wind alone, entered the furnace. The slag and the mass of malleable iron was removed through this channel with iron crooks having wooden handles. The fuel was charcoal.

I think it is doubtful whether a natural blast from the wind alone was. employed, yet it would be quite possible to reduce iron ore in such a furnace by its means.

a Mittheilungen der Antiquarischen Gesellschaft von Zürich, 1871. "Notice sur les forges primitives dans le Jura," par A. Quiquerez, p. 71 et seq. 
Between these furnaces of the Jura and the early forms of those of Carinthia there is a curious similarity; it may, of course, be quite accidental. There is, however, also a similarity between some of the iron objects of La Tène and those of Hallstadt. The question hence arises: Is it possible that in both districts we have the same iron working folk represented, although their remains are not contemporaneous, those of La Tène being of a somewhat later time? The latter is, however, just what we should expect from what we know of the westward movements of races in Europe.

A furnace resembling closely those of the Jura was found recently near Gyalar, in Transylvania, with a block of iron within it. As will be seen from the drawing (fig. 25), ${ }^{a}$ it consists of a shaft, lined with refractory clay, constructed in a cavity cut in the rock, and having for its front side a wall of dressed stones. In this wall is shown the aperture for the admission of the blast. This part, however, is, I think, incorrectly restored; it should be much larger, otherwise the bloom of iron could not be got out. The height of the interior is 5 feet 3 inches.

Another locality for the remains of old iron furnaces of a slightly later period is the neighbourhood of the old Roman camp, the Saalburg, near Homburg vor der Höhe (Hesse). They were carefully explored some years ago by Dr. Beck and Oberst v. Cohausen. ${ }^{\mathrm{b}}$

Very extensive finds of iron objects were made in this vicinity, not only of weapons but of work tools, the most remarkable being two large masses of wrought iron, one weighing 242 kilos, which, according to Beck, are anvils. And here we may note, in passing, an interesting circumstance, the occurrence of three similar blocks of somewhat smaller size in the large hypocaust of the so-called baths before the Porta Decumana, where they formed the enclosing walls of the fire-place. (In the other hypocausts of the Saalburg the fire-places are all built of blocks of basalt.) Beck supposes rightly that the iron blocks were not made by the Romans for this special purpose, but that they were broken anvils which had been discarded at the iron works and thus utilised by the Romans.

In fig. 26 are represented the remains of two of the furnaces, and in fig. 27 a typical furnace as reconstructed by Beck from the data afforded by the ruins of all which he explored. It consists of a nearly cylindrical shaft about 3 feet high, 14 inches in diameter at the bottom and widening out towards the top,

a Journal of the Iron and Steel Institute (London, 1897), lii. 205. The illustration has been kindly lent by the Institute.

Dr. Ludwig Beck, op. cit. i. 514 et seq. 
with sides of clay, which are surrounded by a wall of rough stones against which the earth is piled up in the form of a mound.

The air openings are two or three in number. They are placed at the back of the furnace on the side next the hill slope, and hence we may conclude that
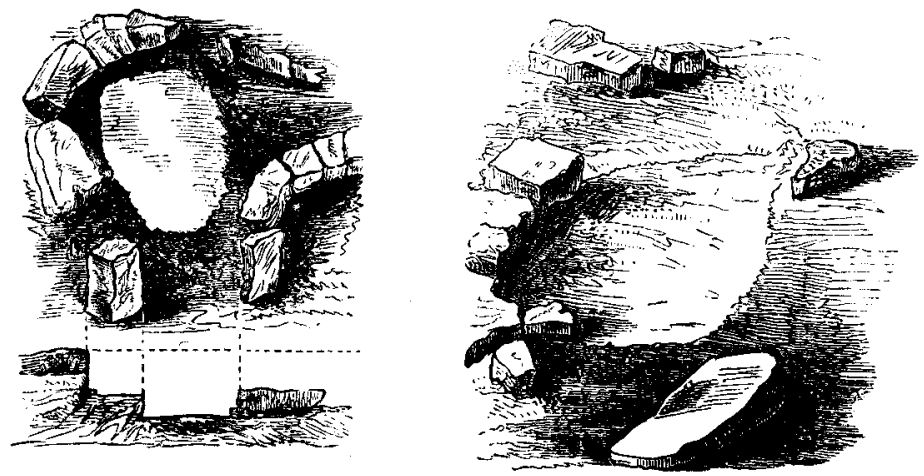

Fig. 26. Remains of ancient iron blast-furnaces found by Dr. Beck near the Saalburg, Ilomburg vor der Höbe.
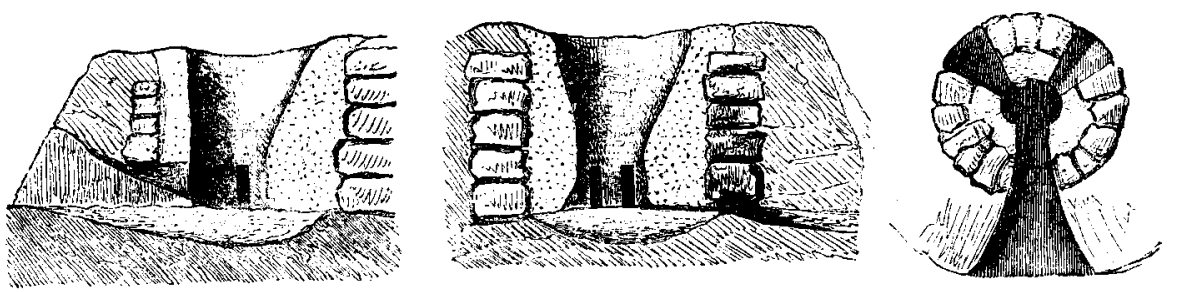

Fig. 27. Ancient iron blast-furnace as restored by Dr. Beck.

the furnace was not worked by the aid of the wind but by a bellows of some kind. No coins or ornaments have been found in or near the sites of these furnaces, and the pottery gives but uncertain indications of the age of this industrial centre. But, from a consideration of the whole evidence available, which is set forth at length in the Die Geschichte des Eisens, Beck concludes that these ironworks were not worked by the Romans but by a native race, both in Roman and pre-Roman times, and that the industry had reached its greatest development about the second century of our era.

A locality for Roman ironworks is the Walloon district, where several furnaces have been found near Faverjeatre.

The process of extracting iron in these ancient furnaces was a rather wasteful

a Dr. Ludwig Beck, op. cit. i. 520, 521, whence this and fig. 27 are borrowed. 
one, as much of the metal was lost in the slags, yet it possessed many undoubted advantages. The iron produced was of the purest character, and it was obtained by a single operation direct from the ore, and in a malleable state. It was not, however, always soft malleable iron, but was often of a steely nature. Even steel itself must frequently have been one of the products as, we have seen, is actually the case in the Japanese furnace, whenever the reduced iron adhered to the furnace walls and was exposed for a considerable time to the carbonising action of the fuel.

The Romans, strange to say, do not appear to have exercised the ingenuity for which they are famous in this branch of metallurgy, but everywhere seem to have adopted, with little if any modifications, the furnaces and processes which were in use by the peoples of the countries they subjugated. This probably was in a great measure due to the work being of a rough and severe character and repugnant to the Roman craftsmen who accompanied the armies. It was hence, doubtless, always carried on by the forced labour of the conquered tribes, and they would naturally continue to use, as far as they were able, the methods and appliances to which they had been accustomed.

This time-honoured process, with its simple furnaces, remained stationary for many centuries, and it was not until mediæval times, when a more powerful blast was obtained by the application of water power to larger and more efficient bellows, that the furnace was further increased in height. The conditions favourable for the production of cast iron, viz. a very high temperature and prolonged contact of the reduced ore with the fuel, resulted; a method of converting this into malleable iron was invented, and the process of iron smelting, as practised in the gigantic furnaces of the present day, was then gradually developed.

I have endeavoured in the foregoing pages to portray, as far as the evidence at present available permits, the beginnings of the metallurgy of copper, tin, and iron in Europe, and to trace from these beginnings the gradual evolution of the processes and appliances employed up to the time of the Fall of the Roman Empire. I fear it is but a fragmentary and inadequate outline of this wide subject which I present to you, yet I hope I have made clear the chief points in the conditions under which the prehistoric metallurgists and their immediate successors carried on their simple operations, and the general features of the rude appliances by means of which they attained their ends.

Much, however, is still obscure and awaits elucidation. For this further explorations of the ancient smelting sites are urgently needed. Many of these 
sites in England and elsewhere have indeed been dug up, but unfortunately too often only by the collector for the "mere gathering of curious relics." This is far from sufficient, and in some cases had better have been left undone. What is of the first importance is a thorough exploration and examination of all the remains which the old metallurgists have left us on their workplaces, especially the foundations and débris of their furnaces, in order that we may ascertain not only what they made, but the manner in which they worked. Such alone can supply the links which are wanting in the chain of evidence needed for the compilation of a complete history of the early metallurgy of Europe. 